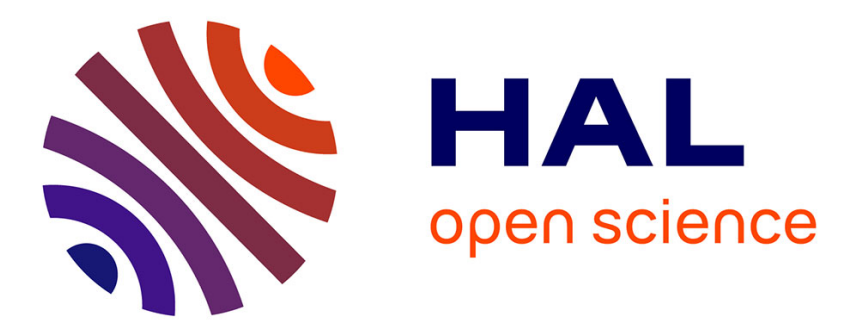

\title{
Sensitivity of the residual topography to single crystal plasticity parameters in Berkovich nanoindentation on FCC nickel
}

\author{
Emile Renner, Yves Gaillard, Fabrice Richard, Fabien Amiot, Patrick \\ Delobelle
}

\section{To cite this version:}

Emile Renner, Yves Gaillard, Fabrice Richard, Fabien Amiot, Patrick Delobelle. Sensitivity of the residual topography to single crystal plasticity parameters in Berkovich nanoindentation on FCC nickel. International Journal of Plasticity, 2016, 77, pp.118 - 140. hal-01256237

\section{HAL Id: hal-01256237 \\ https://hal.science/hal-01256237}

Submitted on 14 Jan 2016

HAL is a multi-disciplinary open access archive for the deposit and dissemination of scientific research documents, whether they are published or not. The documents may come from teaching and research institutions in France or abroad, or from public or private research centers.
L'archive ouverte pluridisciplinaire HAL, est destinée au dépôt et à la diffusion de documents scientifiques de niveau recherche, publiés ou non, émanant des établissements d'enseignement et de recherche français ou étrangers, des laboratoires publics ou privés. 


\title{
Sensitivity of the residual topography to single crystal plasticity parameters in Berkovich nanoindentation on FCC nickel
}

\author{
E. Renner, Y. Gaillard, F. Richard, F. Amiot and P. Delobelle
}

FEMTO-ST Institute, UBFC/CNRS-UMR6174/ENSMM/UTBM, Department of Applied Mechanics, Besançon, France

Keywords: dislocations (A) ; crystal plasticity (B) ; elastic-viscoplastic material (B) ; finite elements $(\mathrm{C})$; Berkovich nanoindentation

Corresponding author, e-mail address: fabrice.richard@univ-fcomte.fr

\begin{abstract}
Fundamental deformation mechanisms of FCC materials under indentation have been probed at the grain scale. Experimental tests have been conducted on large-grained annealed and cold-worked polycrystalline nickel samples with a Berkovich indenter. Indentation axes have been chosen to be close to the three main crystallographic directions [001], [101] and [111]. Pile-ups and slip traces have been revealed around the residual imprints by analysing topographic measurements obtained by atomic force microscopy. It is shown that the indenter orientation in each indentation plane drives pile-ups and slip traces which in turn contain precious information about the crystallographic orientation and the hardening state of the studied grain. Imprint topographies after pile-up formation therefore carry information that one can exploit to assess some intrinsic material properties at the grain scale. A 3D finite element modelling of the nanoindentation test at the grain scale has been developed, making use of crystal plasticity constitutive laws. Six different virtual materials having the same macroscopic behaviour have been built. The simulation results show a good agreement with experimental tests and also a great pile-up sensitivity to interaction matrix components. These results pave the way to the interaction matrix identification using an inverse finite element method.
\end{abstract}

\section{1- Introduction}

Whether based on continuum mechanics or dislocation dynamics, crystal plasticity models involve generally a great number of material parameters, making the description of the phenomena very complete (Méric et al., 1991; Méric and Cailletaud, 1991; Fivel et al., 1998; Chang et al., 2010; Lee and Chen, 2010; Bittencourt, 2012; Dahlberg et al., 2014; Askari et 
al., 2015). In this way, the critical resolved shear stresses for the different slip or twinning systems (CRSS), hardening parameters accounting for dislocation interaction, dislocation annihilation or nucleation terms can lead to models having more than 20 parameters. Thus, it complicates greatly the extraction of each one of them from experimental mechanical data by inverse method. In this aim, the uniqueness and the sensitivity of the identified set of parameters is the relevant question and remains a major scientific challenge. If the classical tensile test along different crystallographic directions on single or bi-crystals (Méric et al., 1991; Méric et al., 1994) appears to be efficient in the case of hardening interaction parameter identification, it remains particularly expensive and limited to materials that can be obtained macroscopically in single or bi-crystalline forms. The identification from the residual topography obtained after an indentation test appears as an alternative solution, as suggested by Zambaldi et al. (Zambaldi et al., 2012, 2015). In fact, pile-up distribution around an indentation imprint performed on a single crystal strongly depends on the indented crystal orientation and "can be used as a fingerprint of the underlying crystal deformation processes" (Zambaldi and Raabe, 2010). Furthermore, this effect has already been numerically reproduced using finite element simulation using crystal plasticity (Wang et al., 2004; Liu et al., 2005, 2008; Zaafarani et al., 2006; Casals et al., 2007; Casals and Forest, 2009; Eidel and Gruttmann, 2007; Eidel, 2011; Alcalá et al., 2008; Zambaldi et al., 2007; Zambaldi and Raabe, 2010; Zambaldi et al., 2012, 2015; Zamanzade et al., 2013; Kucharski et al., 2014; Yao et al., 2014). Some relevant procedures have been developed for the identification of constitutive parameters, as finite element model updating, using indentation and residual imprint data at the macroscopic scale (Bolzon et al., 2004, 2009, 2012; Bocciarelli et al., 2005, 2008; Bocciarelli and Bolzon, 2009; Rauchs and Bardon, 2011; Moy et al., 2011). Similar identification procedures have been investigated at the sub-micron scale with single crystal plasticity models in order to assess critical resolved shear stress (CRSS) values (Zambaldi et al., 2012, 2015; Tasan et al., 2014b, 2014a).

This paper presents a complete experimental study of the anisotropy and the plasticity properties of polycrystalline nickel under Berkovich nanoindentation at a single crystal scale. It is shown, through the AFM topographic measurements of residual indentation imprints, that breaking the indented crystal's material symmetry with the indenter's symmetry is the good way to probe the material constitutive laws. For this reason, the use of Berkovich indenters featuring a three-fold symmetry appears to be particularly interesting for cubic crystals. The influence of the sample hardening rate on the AFM topographic measurements has also been probed by indenting the same sample in two different states: annealed and work-hardened in traction. Crystal plasticity of nickel has been modelled in the size independent single crystal plasticity framework (Méric et al., 1991; Méric and Cailletaud, 1991). Six different virtual materials featuring the same macroscopic behaviour in tension have been built from the 
experimental macroscopic response of our sample and they have been numerically indented using the finite element code Zebulon [http://www.zset-software.com]. Each one of these materials promotes a particular interaction listed in the case of FCC metals (self-hardening, coplanar interaction, Hirth locks, collinear interaction, glissile junctions and Lomer locks). It is shown that if their macroscopic stress-strain curves are the same, the numerical topographies obtained around the residual imprint are strongly different from one virtual material to another, in term of pile-up distribution in number and sizes. Indeed the values of the hardening parameters strongly drive the agreement between numerical and experimental topographies. If the hardening interaction parameters are not identified in the present paper, this constitutes the first step toward a relevant identification procedure using an inverse method from topographic measurements, similar to the ones developed by Zambaldi and Tasan for CRSS values (Zambaldi et al., 2012, 2015; Tasan et al., 2014b, 2014a).

\section{2- Experimental tests}

\section{2-1 Material samples and tensile test}

The experimental part makes use of three polycrystalline nickel samples whose EBSD (Electron Back Scattering Dispersion) pictures are reported in Fig. 1 (Delobelle et al., 2009, 2011).

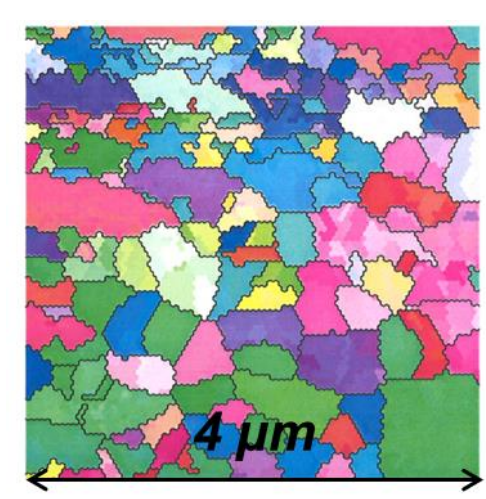

(a) electro-deposed

$$
\emptyset_{\text {grain }} \approx 0.37 \mu \mathrm{m}
$$

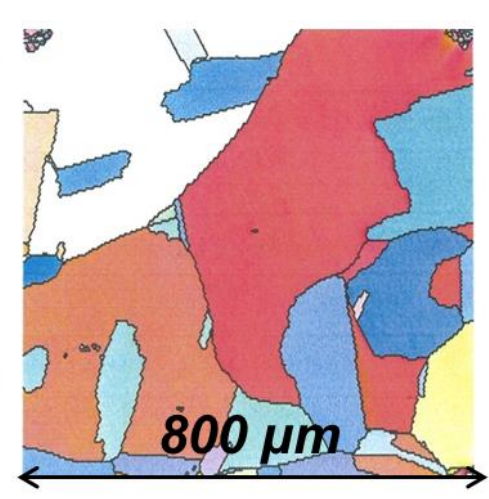

(b) annealed



(c) $30 \%$ work-hardened

111

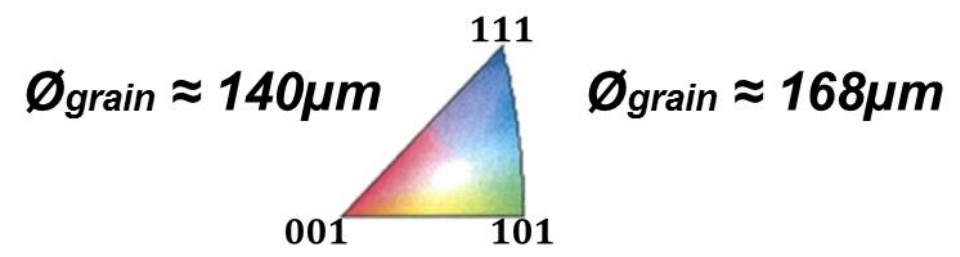

Fig. 1. EBSD measurements of the studied areas on the three polycrystalline nickel samples: (a) electro-deposed sample, (b) annealed sample, (c) 30\% work-hardened sample.

Nickel is a FCC orthotropic material with a Zener anisotropic factor of $f_{\text {ani }}=2 C_{44} /\left(C_{11}-C_{12}\right)=$ 2.44; where $C_{11}, C_{12}$ and $C_{44}$ are the three stiffness tensor components. The first nickel sample 
(a) has very small grains (average grain size about $0.37 \mu \mathrm{m}$ ) and was obtained by electrodeposition with a thickness of $300 \mu \mathrm{m}$. The second one (b) is a $99.9 \%$ pure nickel sample (Goodfellow society) with large grains (average grain size about $140 \mu \mathrm{m}$ ) and was obtained after 3 hours annealing at $900^{\circ} \mathrm{C}$ of a cast ingot. The last one (c) is obtained by work-hardening (30\% in traction) the annealed nickel sample (average grain size of about $168 \mu \mathrm{m}$ ). The sample longitudinal strain has been measured with a strain gauge extensometer and a constant tensile strain rate of $4.10^{-4} \mathrm{~s}^{-1}$ has been applied. The true stress-true strain tensile curve of the annealed material is presented in Fig. 2. All the tested samples were chemically etched with copper sulphate in a hydrochloric acid solution and polished with a neutral alumina suspension.



Fig. 2. Macroscopic true stress-true strain tensile curve of the polycrystalline annealed nickel sample (blue curve); Exponential isotropic hardening law used to model the response (Eq. 14, red curve) ; Numerical true stress-true strain tensile curve of the polycrystalline representative elementary volume composed of 91 randomly oriented grains (Eqs. 7-12, black curve).

\section{2-2 Nanoindentation tests and topography measurements}

Samples have been indented at room temperature using an Anton Paar nanoindenter equipped with a $\mathrm{NHT}^{2}$ (Nano Hardness Tester) head which consists in an indenter tip, its column and a magnet coil which drives the latter [http://www.anton-paar.com]. A Berkovich diamond tip (triangular based pyramid) has been used. Indentations have been performed in load-controlled mode for different maximum forces $P_{m}$ in order to approximately obtain the same maximum indentation depths $h_{m}$ on the three samples. In this way, $P_{m}=90 \mathrm{mN}, 30 \mathrm{mN}$ and $50 \mathrm{mN}$ have been applied for electro-deposited, annealed and cold worked samples, respectively, in order to obtain $h_{m} \sim 900 \mathrm{~nm}$. Supplementary indentation tests have also been 
conducted to obtain $h_{m} \sim 100,300$ and $500 \mathrm{~nm}$. Examples of indentation curves obtained for the three studied samples are given in Fig. 3.

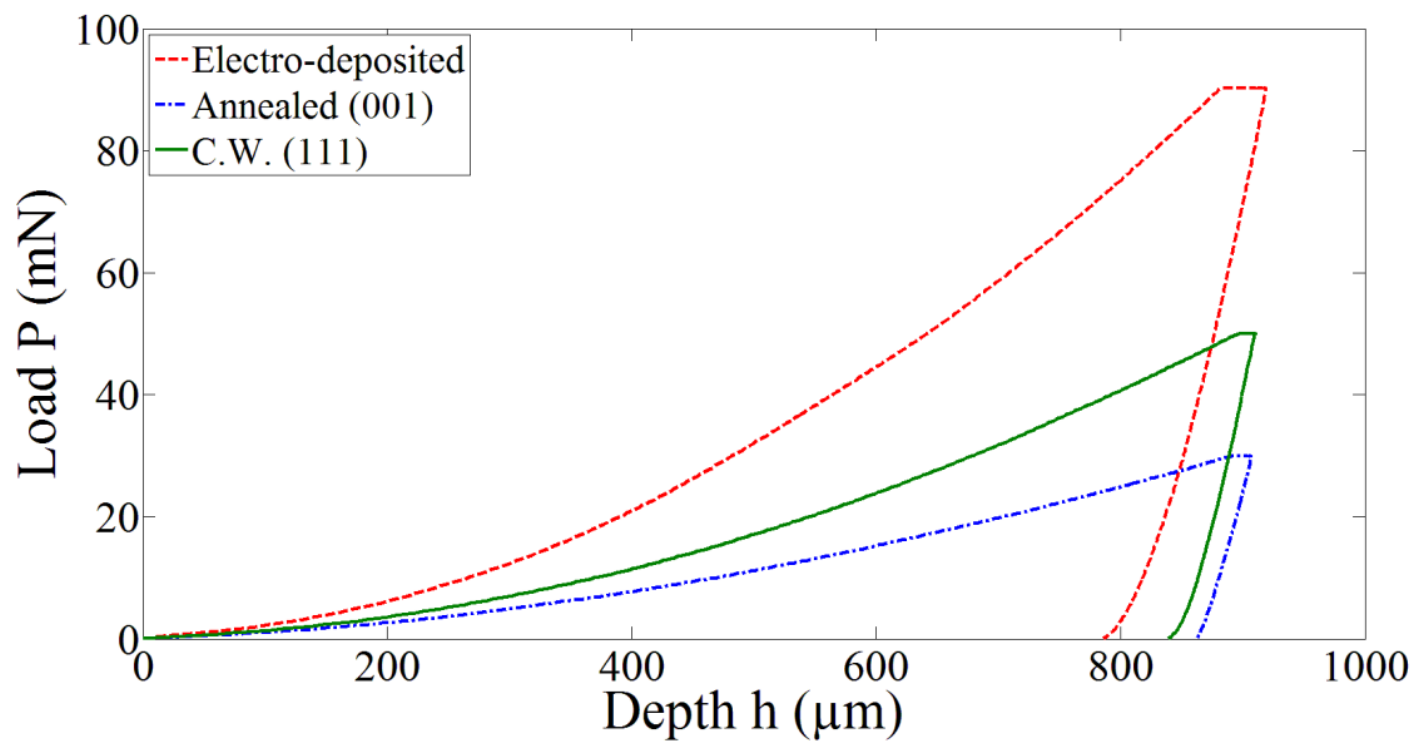

Fig. 3. Typical examples of load-depth curves for the three studied samples: electro-deposited, annealed and coldworked samples.

Combining the EBSD orientation mapping (Fig. 1) with optical recognition, it has been possible to perform indentations in three different crystallographic planes close to the $\{001\},\{101\}$ and $\{111\}$ family of lattice planes. Some measurements have also been carried out on the $\{123\}$ oriented grain of the annealed specimen. Then, the samples have been successively rotated of $30^{\circ}, 60^{\circ}$ and $90^{\circ}$ along the indentation axis in order to study the indenter orientation effect in each indentation planes. For each indentation direction and indenter orientation, three indentations have been performed to assess the repeatability of the results. Indentation imprints have been observed with an atomic force microscope AFM PSIA XE-150 in noncontact mode and analysed with the WSxM software (Horcas et al., 2007). Topographies of the indented areas reveal the pile-up distribution and sizes. A derivative filter has also been applied to the measured topographies to highlight the presence of dislocation slip traces emerging at the surface.

\section{2-3 Correction to the hardness and modulus from topography measurements}

In the following, the projected area is estimated by taking the pile-ups into account in order to yield accurate values for hardness and indentation modulus. In fact, although this correction is one of the more cited justifications in performing this kind of study, the impact of the particular pile-up distribution on the evaluation of hardness and Young modulus is generally overlooked. A method exploiting the topography measurements to correct the values of these 
two mechanical quantities is then proposed. An analysis of the influence of the grain orientations and the hardening of the material on the pile-up corrections is also presented. Hardness $H_{\langle h k l\rangle}$ and indentation modulus $M_{\langle h k l\rangle}$ (Oliver and Pharr, 1992; Vlassak and Nix, 1993, 1994) are defined as follows:

$$
\begin{gathered}
H_{\langle h k l\rangle}=\frac{P_{m}}{A\left(h_{c}\right)} \\
M_{\langle h k l\rangle}=\left[\frac{1}{M_{r}}-\left(\frac{1-v_{i}^{2}}{E_{i}}\right)\right]^{-1} \\
M_{r}=\frac{\sqrt{\pi}}{2 \delta \sqrt{A\left(h_{c}\right)}}\left(\frac{d P}{d h}\right)_{h_{m}} \\
A\left(h_{c}\right)=24.56 h_{c}^{2}+\sum_{i=1}^{8} C_{i} h_{c}^{1 / i^{2}} \text { and } h_{c}=h_{m}-\varepsilon \frac{P_{m}}{\left(\frac{d P}{d h}\right)_{h_{m}}}
\end{gathered}
$$

where $P_{m}$ is the maximum load applied on the indenter, $h_{m}$ the maximum depth and $A\left(h_{c}\right)$ is the projected contact area between the indenter and the material. $E_{i}$ and $v_{i}$ are the Young's modulus and the Poisson's ratio of the indenter, respectively. $\left(\frac{d P}{d h}\right)_{h_{m}}$ is the contact stiffness. $\delta$ and $\varepsilon$ are two geometrical constants depending on the indenter shape. For a Berkovich tip $\delta=$ 1.034 (Oliver and Pharr, 1992, 2004). The two mechanical quantities $H_{\langle h k l\rangle}$ and $M_{\langle h k l\rangle}$ strongly depend on the contact area $A$ (Eq. 4). $A$ is classically determined by evaluating the contact depth by using the Oliver and Pharr method (Oliver and Pharr, 1992) and by calibrating the exact shape of the indenter (tip rounding approximated by a fitting a $8^{\text {th }}$ order polynomial) with a material having a known Young's modulus (fused silica herein). Pile-ups increase the contact area between the material and the indenter, systematically leading to erroneous $A$ values and consequently to an overestimation of the hardness and the indentation modulus values. Methods have been developed to better estimate the modified projected area due to pile-ups (McElhaney et al., 1998; Kese et al., 2005; Kese and Li, 2006) and to correct the hardness and indentation modulus quantities (McElhaney et al., 1998; Kese et al., 2005; Kese and Li, 2006; Delobelle et al., 2009, 2011; Gale and Achuthan, 2014). Although the pile-up issue is well known in the nanoindentation literature, it is unfortunately usually neglected. Furthermore, the anisotropy of the pile-up distribution around the residual imprint complicates the evaluation of the projected contact area for single crystal material and is generally not considered in the 
above-mentioned methods (Kese et al., 2005; Kese and Li, 2006). As shown in Fig. 4, a better approximation of the real projected contact area is defined as:

$$
A_{\text {appr. }}=A\left(h_{c}\right)+A_{\text {pile-up }}
$$

with:

$$
A_{\text {pile-up }}=\frac{1}{2 \tan \alpha} \sum_{i=1}^{N} a_{i} w_{i}
$$

Where $N$ is the number of pile-ups formed around the indentation imprint and $\alpha$ the projection angle of the pile-up contact area on the indented plane. $w_{i}$ and $a_{i}$ are the width and maximum height of the $i^{\text {th }}$ pile-up, respectively. The contact surface $A_{\text {pile-up }}$ between the pile-ups and the indenter is approached by a triangle, whose dimension and tilt are used to determine $a_{i}$ and $w_{i}$ (Fig. 4, example on the electro-deposited nickel sample).
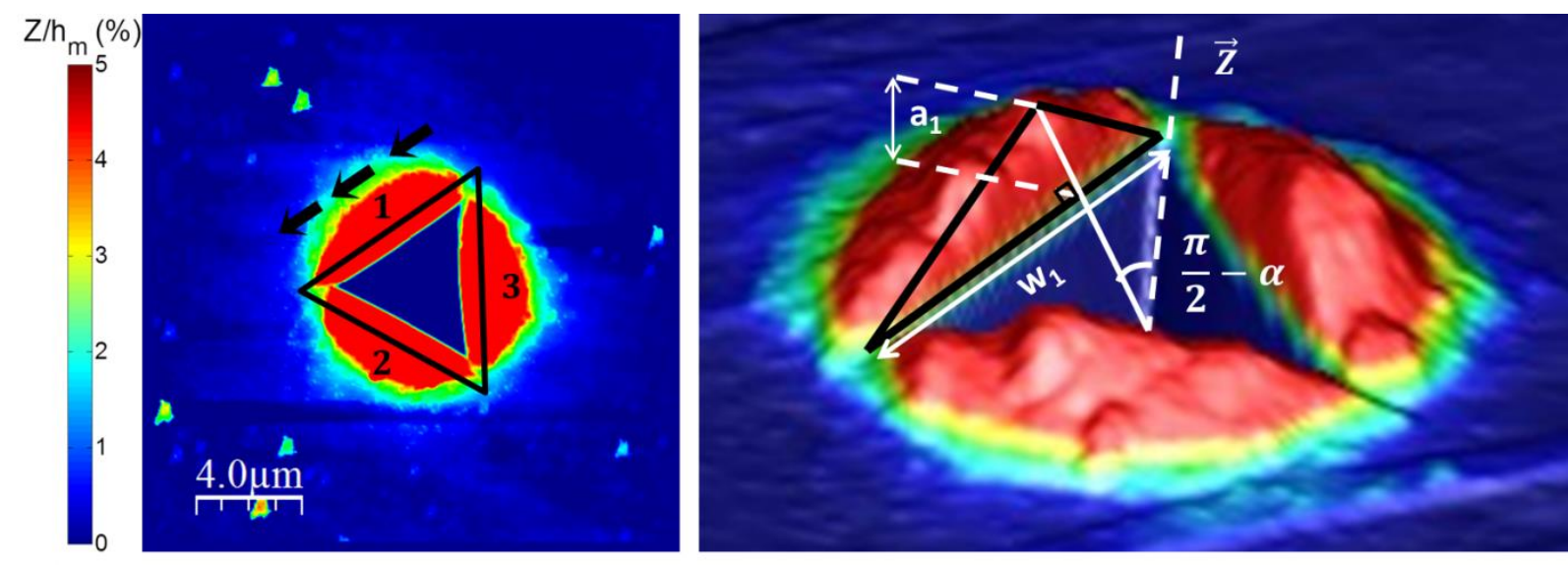

Fig. 4. Approximation of the real projected contact area resulting from pile-up formation: width $w_{i}$ and height $a_{i}$ of each pile-up around the imprint are considered to determine the projected area using triangles. Example on the electro-deposited nickel sample (quasi-isotropic material).

Fig. 5 shows, for the three studied specimens and for a given $\langle h k l\rangle$ grain orientation, the quasilinear dependency between the sum of the maximum heights $\sum a_{i}$ of the pile-ups around imprint and the indentation depths $h_{m}$. Moreover, for a given grain orientation, $\sum a_{i}$ is about two to three times higher for the cold-worked specimen than for the annealed sample. This nicely agrees with reported results (McElhaney et al., 1998; Casals et al., 2007; Alcalá et al., 2008) showing that the pile-up heights amplitude is a decreasing function of the plastic strain hardening modulus. 


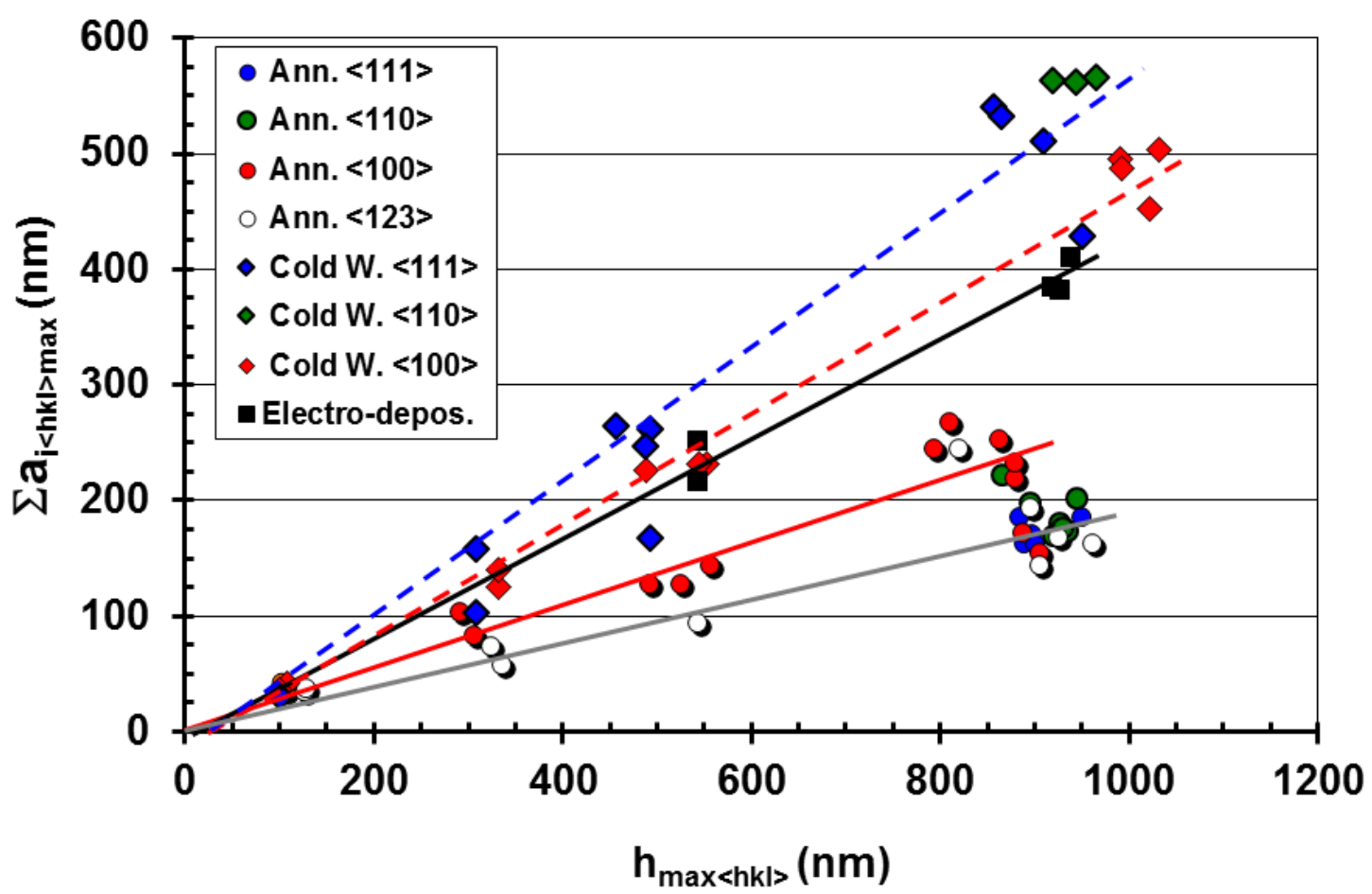

Fig. 5. Sum of the pile-up heights as a function of the indentation depths for different grain orientations. Cases of annealed and cold-worked specimens.

The pile-up correction results estimated through the relations (5) and (6) are reported in Fig. 6 for the annealed and work-hardened polycrystalline nickel samples. Note that the corrected values of the indentation modulus are in a good agreement with those evaluated from the closed-forms proposed by Vlassak \& Nix (Vlassak and Nix, 1993, 1994) and Delobelle et al. (Delobelle et al., 2009, 2011) with $C_{11}=248 \mathrm{GPa}, C_{12}=153 \mathrm{GPa}$ and $C_{44}=116 \mathrm{GPa}$. Concerning the electro-deposited nickel (very small grains), whatever the position of the indentation imprints on the specimen, the indentation modulus is found constant. The experimental value $M=232 \mathrm{GPa}$ obtained after pile-up correction is very close to the theoretical one (Fig. 6a) and at the indentation scale the material can be considered as isotropic.

Pile-up corrections for the annealed material lower the estimate for the indentation modulus by about 3-5\% and hardness determined for $h_{m} \sim 900 \mathrm{~nm}$ by about $5-9 \%$. As previously shown in Fig. 5, pile-ups are quite small due to the high strain-hardening modulus $H_{p}\left(H_{p} \sim 2600 \mathrm{MPa}\right.$ at $\varepsilon^{p} \sim 3 \%$, Fig. 2). Contrariwise, the work-hardened sample presents a low strain-hardening modulus $\left(H_{p} \sim 800 \mathrm{MPa}\right.$ at $\varepsilon^{p} \sim 30 \%$, (Haddou, 2003)) and pile-ups are larger than for the previous sample (Fig. 5). Consequently, the indentation modulus is reduced by about $8-10 \%$ and the hardness by about $16-20 \%$, thus highlighting the necessity of such correction for materials with low plastic hardening modulus. 
Moreover, for annealed material and according to reported results (Vlassak and Nix, 1994) the hardness is almost independent of the grain orientation contrariwise to the work-hardened state as shown in Fig. 6b: $H_{\langle 100\rangle}<H_{\langle 110\rangle}<H_{\langle 111\rangle}$ (Delobelle et al., 2009, 2011).
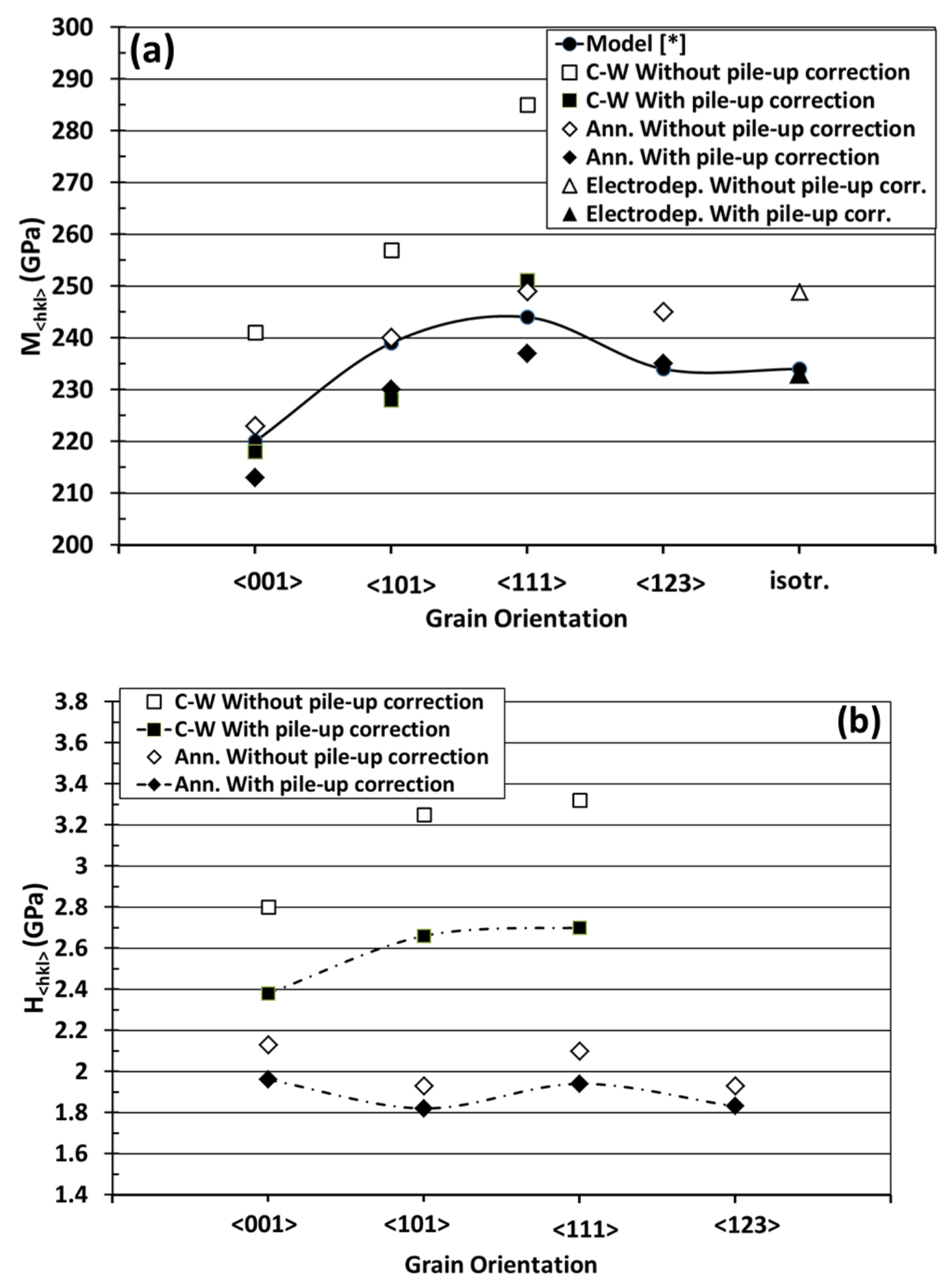
Fig. 6. Indentation modulus (a) and hardness (b) values without and with pile-up corrections as a function of the grain orientations for electro-deposited, annealed and work-hardened samples. [ $\left.{ }^{\star}\right]$ closed-forms proposed by Vlassak \& Nix (Vlassak and Nix, 1993, 1994) and Delobelle et al. (Delobelle et al., 2011, 2009).

\section{3- Numerical modelling}

\section{3-1 Single crystal plasticity constitutive laws}

If the grain size is large compared to the dimension of the residual imprint, grain interaction effects on the considered grain can be neglected. This study thus lies under a single crystal plasticity framework at least for the second and third samples. Simulations have been performed under a large deformation framework. The stiffness tensor $\overline{\bar{C}}$ was considered to model the single crystal elastic response, which is composed of three terms $C_{11}, C_{12}$ and $C_{44}$ due to the fact that nickel presents a FCC structure. The Méric-Cailletaud size independent single crystal plasticity model has been used to describe its viscoplastic behaviour (Méric et al., 1991; Méric and Cailletaud, 1991; Fivel, 2004; Cailletaud, 2009). In this model, the transformation gradient $\overline{\bar{F}}$ is decomposed as follows:

$$
\overline{\bar{F}}=\overline{\overline{F^{e}}} \overline{\overline{F^{p}}}
$$

where $\overline{\overline{F^{e}}}$ is the transformation gradient due to elastic strain and lattice rotation. For FCC single crystal, $\overline{\overline{F^{p}}}$ is the transformation gradient due to plastic shear strain in each of the 12 slip systems $(\langle 110\rangle\{111\})$ listed in the Table 1, defined by the normal vectors of the slip planes $\overline{n^{s}}$ $(\langle 111\rangle)$ and the slip directions $\overline{l^{s}}(\langle 110\rangle)$ :

$$
\dot{\overline{F^{p}}} \overline{\bar{F}^{p}}-1=\sum_{s=1}^{12} \gamma^{s} \overline{l^{s}} \otimes \overline{n^{s}}
$$

The inelastic flow $\gamma^{s}$ is governed by a Norton power law: 


$$
\dot{\gamma^{s}}=\left\langle\frac{\left|\tau^{s}\right|-r^{s}}{K}\right\rangle^{n} \operatorname{sign}\left(\tau^{s}\right), \text { with }\langle\bullet\rangle=\left\{\begin{array}{c}
\bullet \text { if } \bullet>0 \\
0 \text { if } \bullet \leq 0
\end{array}\right.
$$

where $n$ and $K$ are the viscosity parameters. The resolved shear stress on each slip system $\tau^{s}$ is given by:

$$
\tau^{s}=\overline{\overline{m^{s}}}: \overline{\bar{\sigma}} \text { with } \overline{\overline{m^{s}}}=\frac{1}{2}\left(\overline{l^{s}} \otimes \overline{n^{s}}+\overline{n^{s}} \otimes \overline{l^{s}}\right)
$$

where $\overline{\bar{\sigma}}$ is the Cauchy stress tensor and $\overline{\overline{m^{s}}}$ is the Schmid tensor. During the indentation test the loading is essentially monotonic and consequently the hardening has been considered as isotropic (no kinematical hardening) through the $r^{s}$ variable:

$$
r^{s}=r_{0}+q \sum_{r=1}^{12} h^{s r}\left[1-\exp \left(-b v^{r}\right)\right], \text { with } \dot{v}^{r}=\left|\dot{\gamma^{r}}\right|
$$

where the cumulated plastic strain is noted $v^{r} . b$ and $q$ are material parameters. $r_{0}$ is the critical resolved shear stress, $h^{s r}$ are the components of the interaction matrix $\overline{\bar{H}}$ (12x12 components) which depends on 6 parameters $\left(h_{1}, h_{2}, h_{3}, h_{4}, h_{5}, h_{6}\right)$ (see Eq. (12)).

$$
\overline{\bar{H}}=\left[\begin{array}{cccccccccccc}
h_{1} & h_{2} & h_{2} & h_{4} & h_{5} & h_{5} & h_{5} & h_{6} & h_{3} & h_{5} & h_{3} & h_{6} \\
& h_{1} & h_{2} & h_{5} & h_{3} & h_{6} & h_{4} & h_{5} & h_{5} & h_{5} & h_{6} & h_{3} \\
& & h_{1} & h_{5} & h_{6} & h_{3} & h_{5} & h_{3} & h_{6} & h_{4} & h_{5} & h_{5} \\
& & & h_{1} & h_{2} & h_{2} & h_{6} & h_{5} & h_{3} & h_{6} & h_{3} & h_{5} \\
& & & & h_{1} & h_{2} & h_{3} & h_{5} & h_{6} & h_{5} & h_{5} & h_{4} \\
& & & & & h_{1} & h_{5} & h_{4} & h_{5} & h_{3} & h_{6} & h_{5} \\
& & & & & & h_{1} & h_{2} & h_{2} & h_{6} & h_{5} & h_{3} \\
& & & S y m & & & & h_{1} & h_{2} & h_{3} & h_{5} & h_{6} \\
& & & & & & & & h_{1} & h_{5} & h_{4} & h_{5} \\
& & & & & & & & h_{1} & h_{2} & h_{2} \\
& & & & & & & & & h_{1} & h_{2} \\
& & & & & & & & & & h_{1}
\end{array}\right]
$$

Diagonal terms define self-hardening $\left(h_{1}\right)$ and off-diagonal terms define latent hardening: coplanar interaction $\left(h_{2}\right)$, Hirth locks $\left(h_{3}\right)$, collinear interaction $\left(h_{4}\right)$, glissile junctions $\left(h_{5}\right)$ and Lomer locks $\left(h_{6}\right)$ (Franciosi, 1985; Wu et al., 1991; Bassani and Wu, 1991).

The material parameters, $b, q, r_{0}$ and $h^{s r}\left(h_{1}, h_{2}, h_{3}, h_{4}, h_{5}, h_{6}\right)$ for the nickel are not available in the literature and their choice is discussed in the section 3-3. The integration of equations (7-12) can provide the tensile response $(\sigma, \varepsilon)_{<h k l>}$ of a single crystal oriented in the $\langle h k l\rangle$ 
direction. In a first approximation and provided that the parameters set is correct, the average of the tensile response $\sigma_{<h k l>}$ for four different well distributed crystallographic orientations $\langle h k l\rangle$ in the stereographic standard triangle (see 3-3) should approach the macroscopic tensile curve of the polycrystalline sample. Hence, the latter could be compared to the experimental macroscopic tensile response of the polycrystalline sample to validate a crystal plasticity parameters set $\left(K, n, b, q, r_{0}, h^{s r}\right)$.

\begin{tabular}{|c|c|c|}
\hline Plane & Direction & System $s$ \\
\hline \multirow{3}{*}{ B: (111) } & {$[\overline{1} 01]$} & $1: \mathrm{B} 4$ \\
& {$[0 \overline{1} 1]$} & $2: \mathrm{B} 2$ \\
& {$[\overline{1} 10]$} & $3: \mathrm{B} 5$ \\
\hline \multirow{3}{*}{ D: $(1 \overline{1} 1)$} & {$[\overline{1} 01]$} & $4: \mathrm{D} 4$ \\
& {$[011]$} & $5: \mathrm{D} 1$ \\
& {$[110]$} & $6: \mathrm{D} 6$ \\
\hline \multirow{3}{*}{ A: $(\overline{1} 11)$} & {$[0 \overline{1} 1]$} & $7: \mathrm{A} 2$ \\
& {$[110]$} & $8: \mathrm{A} 6$ \\
& {$[101]$} & $9: \mathrm{A} 3$ \\
\hline \multirow{3}{*}{ C: $(11 \overline{1})$} & {$[\overline{1} 10]$} & $10: \mathrm{C} 5$ \\
& {$[101]$} & $11: \mathrm{C} 3$ \\
& {$[011]$} & $12: \mathrm{C} 1$ \\
\hline
\end{tabular}

Table 1. Notation for the FCC slip systems according to Schmid \& Boas convention (Schmid and Boas, 1935).

\section{3-2 Finite element modelling: indentation and tensile test}

To account for the material anisotropy and the indenter shape, three dimensional numerical simulations of the nanoindentation test have been performed using the finite element code Zebulon. The model includes 19564 volume elements (C3D8). All calculations correspond to an indentation test controlled in displacement along $\vec{Z}$ indentation axis, with a maximum indentation depth of $h_{m}=900 \mathrm{~nm}$. This indentation depth is large enough compared to the characteristic length of the indentation size effect in the nickel sample studied. This has been confirmed by experimental measurements of the load over squared stiffness (directly proportional to hardness) at different indentation depths. As shown in Fig. 7, studied grains are modelled by a cylinder whose radius and height are 40 times larger than the maximum indentation depth. The lower cylinder surface is clamped and the lateral surface is free. The Berkovich tip is considered as rigid. The contact problem is solved with a direct method called 
flexibility method (Francavilla and Zienkiewicz, 1975; Sachdeva and Ramakrishnan, 1981; Wronski, 1994; Jean, 1995). The Coulomb law is used for ensuring contact between the upper cylinder surface and the Berkovich indenter, with a null friction coefficient. Indeed, for the indenter geometry used, the friction effect is negligible on the indentation curve (Taljat et al., 1998) and minor on the residual indentation topography compared to the hardening parameters studied. The mesh is refined near the contact region (mesh size $257 \mathrm{~nm}$ ). All the numerical topographies have been retrieved after the indenter unloading phase and total elastic recovery.

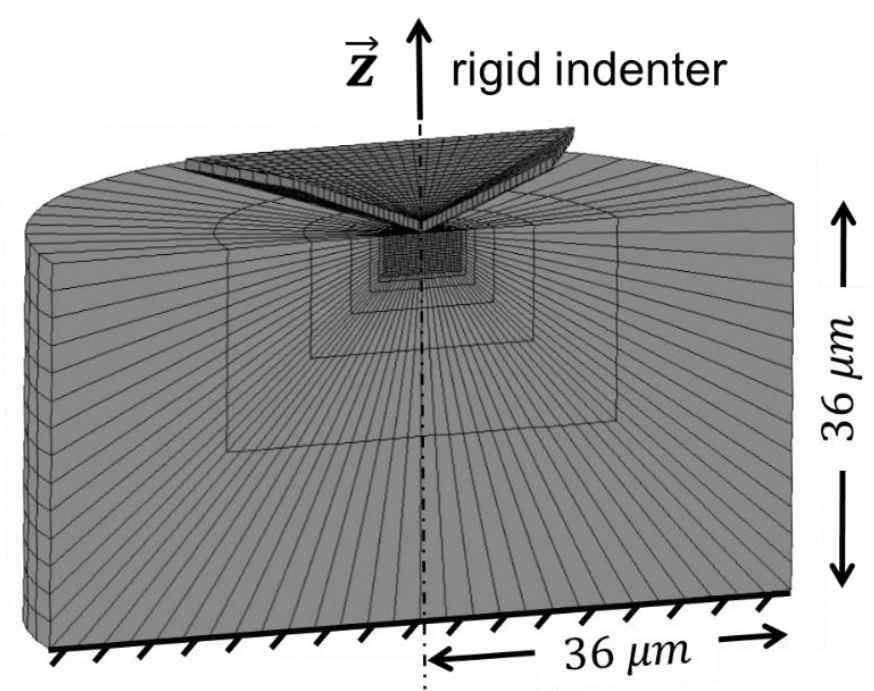

Fig. 7. Mesh used in the finite element simulations (cross sectional view).

A finite element modelling of a tensile test on a polycrystalline representative elementary volume (REV) has also been developed. The model (Fig. 8) is a cube composed of 2489 volume elements (C3D8) and represents a polycrystalline sample with 91 randomly-oriented grains. This model has been generated using the Neper software (Quey et al., 2011) and the boundary conditions are illustrated in Fig. 8. As described in section. 3-3, it is used to validate the crystal plasticity material parameters estimated using the macroscopic tensile test and used for the nanoindentation simulations. 


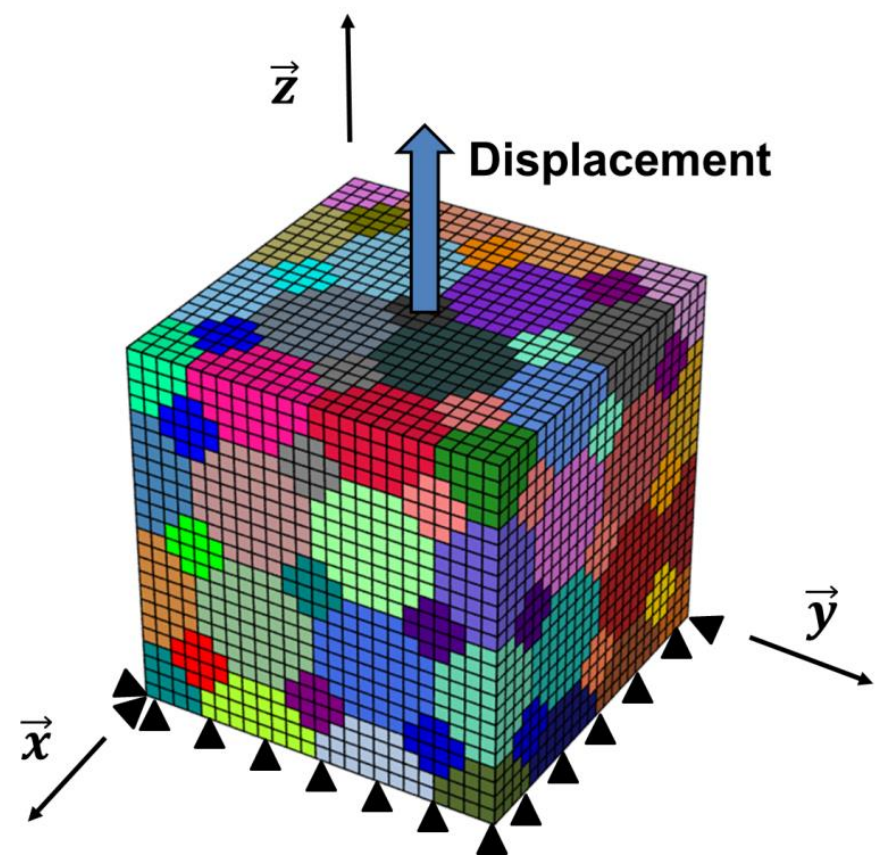

Fig. 8. Finite element tensile test modelling: polycrystalline representative elementary volume composed of 91 randomly oriented grains.

\section{3-3 Material parameters estimation for the single plasticity constitutive laws}

This section focuses on the choice of the viscosity and plastic parameters: $K, n, b, q, r_{0}$ and $h^{s r}\left(h_{1}, h_{2}, h_{3}, h_{4}, h_{5}, h_{6}\right)$ for the modelling of the annealed nickel sample behaviour. The elastic stiffnesses $C_{11}=248 \mathrm{GPa}, C_{12}=153 \mathrm{GPa}$ and $C_{44}=116 \mathrm{GPa}$ are taken from the literature (Delobelle et al., 2009).

By combining the equations (9) and (11) at the grain scale, the resolved shear stress on each slip system $\tau^{s}$ becomes:

$$
\left|\tau^{s}\right|=\underbrace{r_{0}+q \sum_{r=1}^{12} h^{s r}\left[1-\exp \left(-b v^{r}\right)\right]}_{r^{s}}+\underbrace{K\left(\dot{\gamma}^{s}\right)^{1 / n}}_{\sigma_{\text {visco }}^{S}}=r^{s}+\sigma_{\text {visco }}^{s}
$$

Equation (13) defines the resolved shear stress as the sum of a hardening term $r^{s}$ and a viscosity term $\sigma_{\text {visco }}^{s}$. Let us first consider the viscosity term $\sigma_{v i s c o}^{s}$.

Values for the viscosity parameters of metallic materials at room temperature have been chosen as: $K=8 \mathrm{MPa} . \mathrm{s}^{1 / n}$ and $n=7$. With this couple of parameters, a strain rate variation of $10^{3}$ leads to a change of the shear stress component $\sigma_{v i s c o}^{s}$ of about $3 \mathrm{MPa}$, which agrees with the commonly measured values for the $\mathrm{Ni}$ (Rao and Varma, 1993). It is worth noting that loading and unloading steps during the indentation tests last $30 \mathrm{~s}$.

The macroscopic tensile response of the polycrystalline annealed nickel sample (Fig. 2) is then used to estimate the microscopic hardening parameters. The tensile curve is first approached 
as an average of different single crystals behaviours composing the sample. According to Eq. (11) and Eq. (13), neglecting the viscosity term which is very small, the experimental stressstrain curve of the polycrystal is fitted with an exponential isotropic hardening law (Fig. 2):

$$
\sigma=R_{0}+Q\left[1-\exp \left(-B \varepsilon^{p}\right)\right]
$$

$\varepsilon^{p}$ is the uniaxial plastic strain, $R_{0}=80 \mathrm{MPa}$ is the initial yield stress and $R_{0}+Q=500 \mathrm{MPa}$ is the asymptotic value to which the stress tends for very large deformations. $B=8$ is a constant accounting for the curvature of the stress-strain curve above the yield stress (Fig. 2). Classical relations exist between microscopic (Eq.13) and macroscopic (Eq.14) parameters (Bishop and Hill, 1951a, 1951b):

$$
\begin{gathered}
\left.r_{0}=\frac{R_{0}}{\bar{M}}, \text { with } \bar{M} \approx 3 \text { (Taylor factor for FCC structure }\right) \\
b=B \bar{r}, \text { with } \bar{r} \approx 2(\text { Nye factor for FCC structure })
\end{gathered}
$$

Hence, the values $r_{0}=26.7 \mathrm{MPa}, b=16$ have been deduced. The value of the material parameter $q$ has then been determined using numerical tensile tests performed on single crystal REV for four different crystallographic orientations, i.e: [001], [101], [111] and [123], for a given $\left(C_{11}, C_{12}, C_{44}, K, n, r_{0}, b, h^{s r}\right)$ set of parameters. Note that these four directions are the most extreme orientations of the stereographic standard triangle. It has been assumed that the mean response of the tensile simulations in these four characteristic orientations is representative of the polycrystalline sample behaviour for relatively low strain. Hence, the identification procedure considers the sum of squared deviations from the experimental to the numerical tensile responses as a cost function whose minimiser is $q$. The result obviously depends on the matrix interaction components. Let us thus formally write the following relation between the microscopic $q$ and macroscopic $Q$ quantities:

$$
q=Q f\left(h_{1}, h_{2}, h_{3}, h_{4}, h_{5}, h_{6}\right)
$$

The $f$ function in Eq. (17) has no simple explicit closed-form expression. The hardening matrix has been initially chosen proportional to the identity matrix - self-hardening: $h_{1}=100, h_{2-6}=$ 0 (Sabnis et al., 2013), which yields an identified value of the parameter $q=1.3 \mathrm{MPa}$. The flow chart in Fig. 9 summarizes the identification procedure used for calculating the material parameters. 


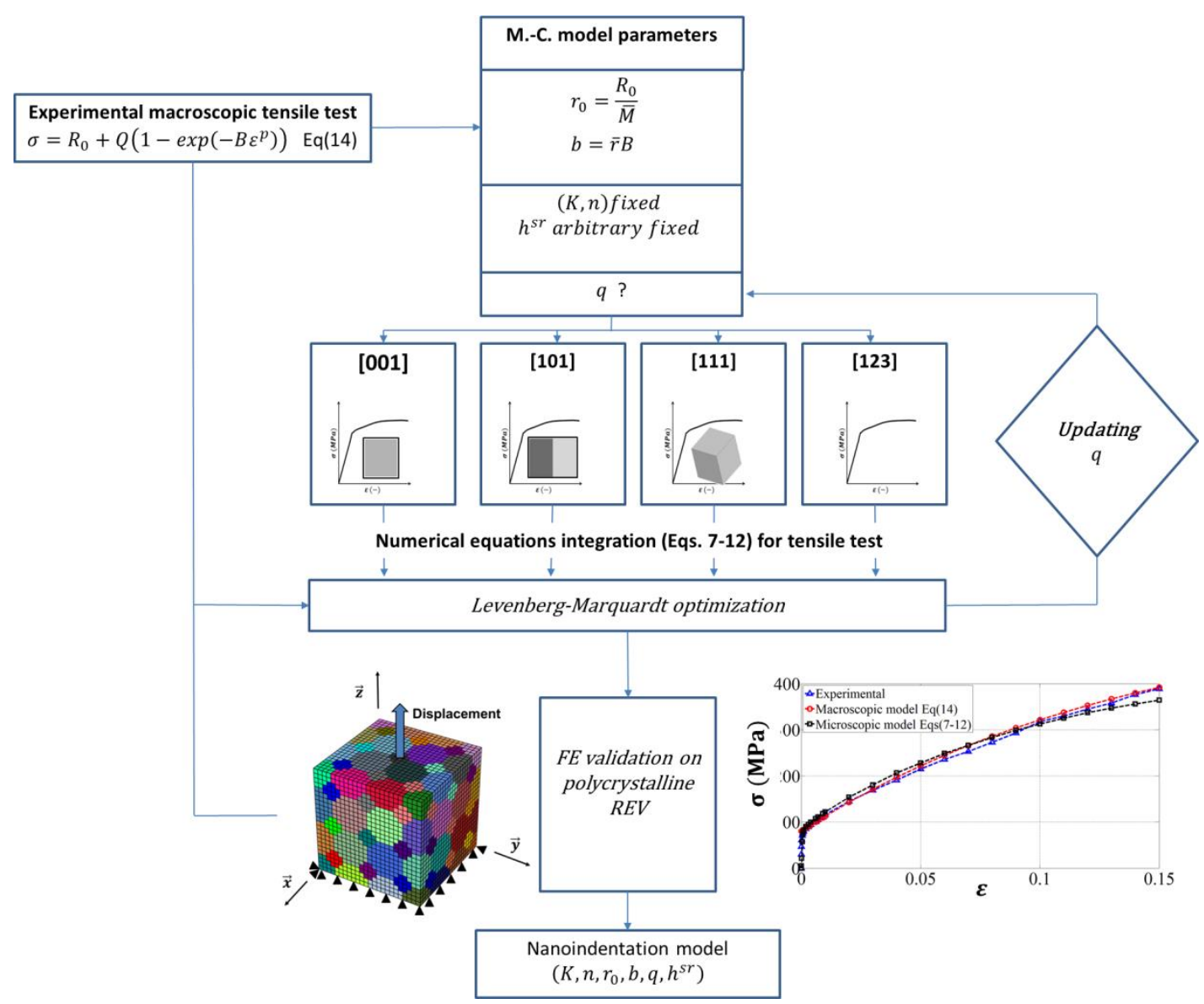

Fig. 9. Flow chart summarizing the identification procedure used to determine the material plastic parameters in the nanoindentation model.

The parameter set previously determined has been numerically validated using the finite element model of the tensile test on the polycrystalline REV described in section 3-2 (Fig. 8). As shown in Fig. 2, the obtained stress-strain nicely fits the experimental tensile curve up to $10 \%$ strain. The response is slightly underestimated at larger strains. This can be explained by the fact that no attention has been paid to the localization of the plastic strain. Also the interaction effects between adjacent grains should no longer be neglected above a certain strain level. From a macroscopic point of view, it should be highlighted that the representative plastic strain is about 3.3\% with a Berkovich indenter (Dao et al., 2001), which is thus lower than $10 \%$. This particular set of parameters (self-hardening only) is thus chosen for the modelling of the annealed nickel sample behaviour under indentation. The values of the identified parameters for the annealed sample behaviour are reported in the Table 2. 


\begin{tabular}{|c|c|c|c|c|c|c|c|c|c|c|c|c|}
\hline \multirow{2}{*}{ Elasticity } & \multicolumn{2}{|l|}{ Viscosity } & \multicolumn{9}{|c|}{ Hardening parameters } & \multirow{2}{*}{ Fig. } \\
\hline & $K\left(\mathrm{MPa} \cdot \mathrm{s}^{1 / \mathrm{n}}\right)$ & $n$ & $r_{0}(\mathrm{MPa})$ & $b$ & $q(\mathrm{MPa})$ & $h_{1}$ & $h_{2}$ & $h_{3}$ & $h_{4}$ & $h_{5}$ & $h_{6}$ & \\
\hline$C_{11}$ & \multirow{6}{*}{8} & \multirow{6}{*}{7} & \multirow{6}{*}{26.7} & \multirow{6}{*}{16} & 1.3 & 100 & 0 & 0 & 0 & 0 & 0 & $10,11,20$ \\
\hline$=248000 \mathrm{MPa}$ & & & & & 20 & 1 & 45 & 1 & 1 & 1 & 1 & 20 \\
\hline$C_{12}$ & & & & & 20.5 & 1 & 1 & 45 & 1 & 1 & 1 & 20 \\
\hline$=153000 \mathrm{MPa}$ & & & & & 20 & 1 & 1 & 1 & 89 & 1 & 1 & 20 \\
\hline$C_{44}$ & & & & & 10 & 1 & 1 & 1 & 1 & 23 & 1 & $18,19,20$ \\
\hline$=116000 \mathrm{MPa}$ & & & & & 20 & 1 & 1 & 1 & 1 & 1 & 45 & 20 \\
\hline
\end{tabular}

Table 2. Material parameters calibration for the annealed sample using the procedure in section 3-3.

As further shown, the advantage of this identification procedure is its capability to adjust the macroscopic stress-strain curve whatever the choice of the components values of the interaction matrix $h^{s r}$.

\section{3-4 Analysis of the numerical nanoindentation results}

Figure 10 shows an example in cross section (in the (010) plane) of the deformed mesh at maximum indentation depth $(900 \mathrm{~nm})$. The same mechanical quantities are shown in the top view in Fig. 11. One can observe the numerical results of the cumulated plastic strain on each slip system and the total cumulated plastic strain at the maximum indentation depth. It is observed that all slip systems are activated. However, this type of information cannot be directly compared to surface experimental data. For this reason, only experimental and numerical residual indentation imprint topographies will be compared. 


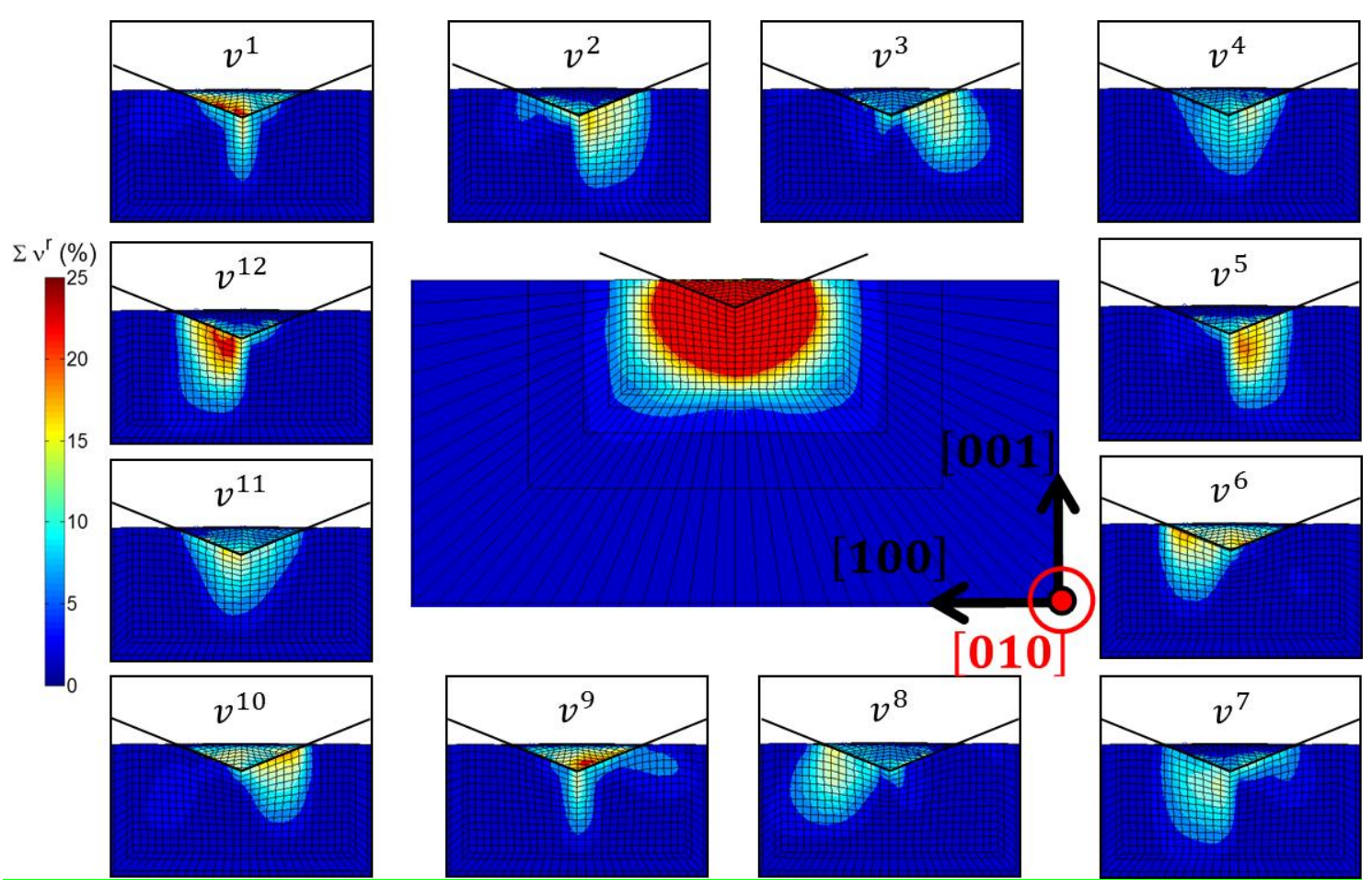

Fig. 10. Details of a (001) Berkovich indentation plastic zone obtained on a (010) cross section (same as in Fig. 7): the total cumulated plastic strain (at the centre of the figure), and the ones obtained on the 12 slip systems at the maximum indentation depth (with transparent indenter). Hardening parameters used for simulating the virtual material: $q=1.3 \mathrm{MPa}, h_{1}=100, h_{i}=0$ (Table 2). 

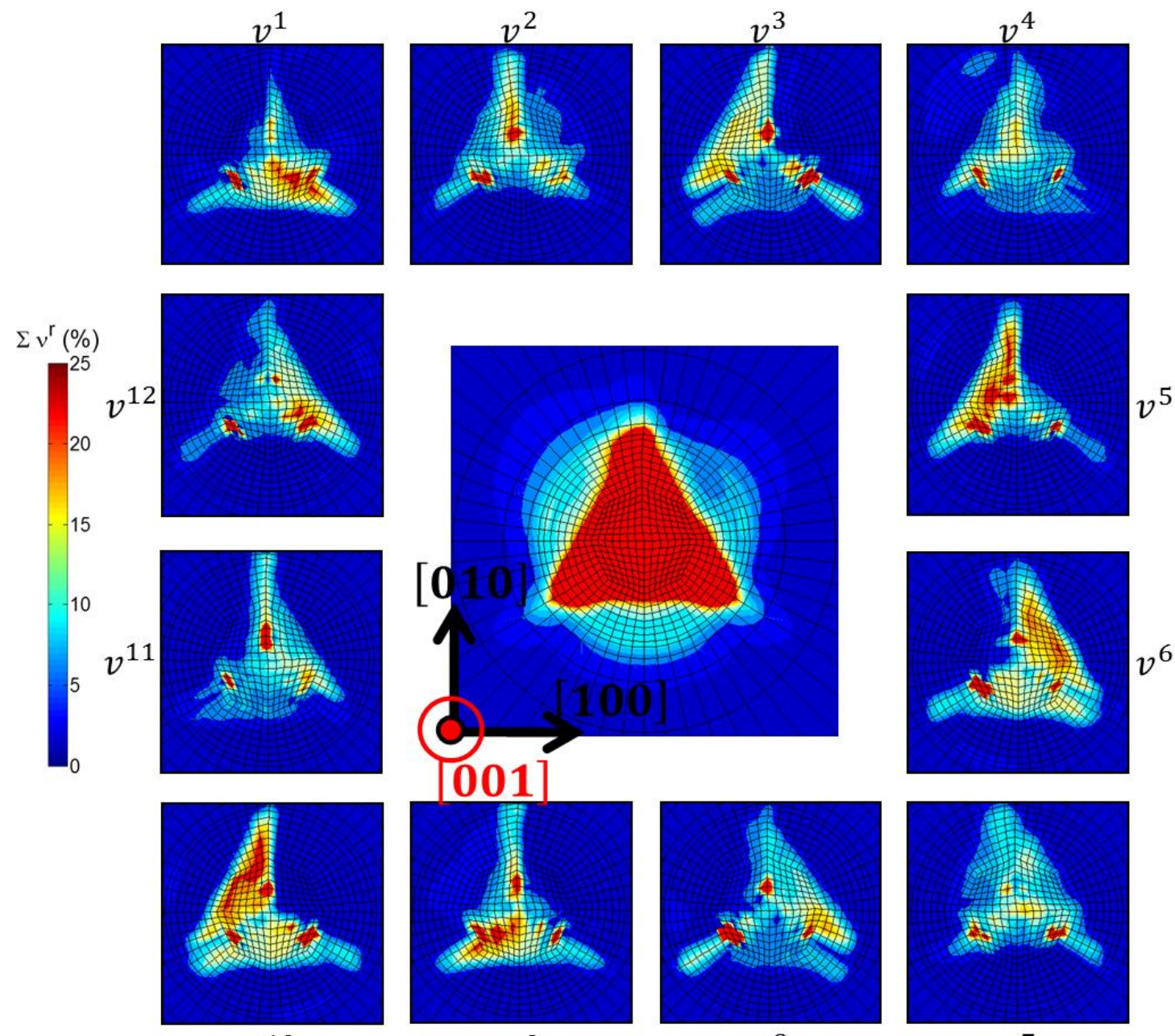

$v^{10}$

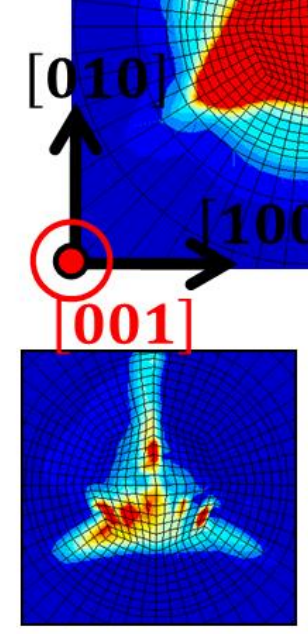

$v^{9}$
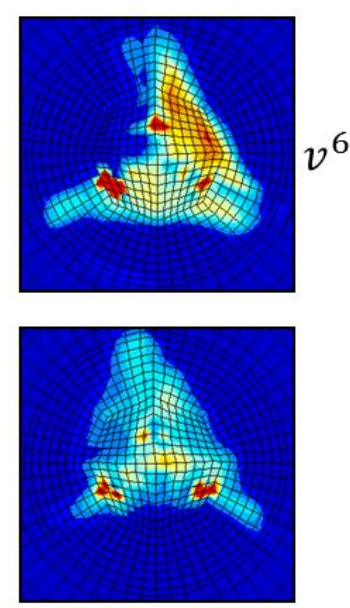

$v^{7}$

Fig. 11. Details of a (001) Berkovich indentation plastic zone obtained in the top view: the total cumulated plastic strain (at the centre of the figure), and the ones obtained on the 12 slip systems at the maximum indentation depth. Hardening parameters used for simulating the virtual material: $q=1.3 \mathrm{MPa}, h_{1}=100, h_{i}=0$ (Table 2).

\section{4- Results and discussions}

\section{4-1 Topography measurements}

In this section, topography and derivative measurements of the indentation areas observed by AFM are presented. Examples of load-depth curves for the three studied samples have been presented in Fig. 3.

Results obtained on the electro-deposed polycrystalline nickel sample are shown in section 4-1-1 for three different indenter orientations: $0^{\circ}, 60^{\circ}$ and $90^{\circ}$ (Fig. 12). In section 4-12 , results obtained on the annealed polycrystalline nickel sample are presented. Three indentation directions close to the [001], [101] and [111] crystallographic directions are investigated through three different grains (Fig. 13). Effects of indenter rotation is also analysed 
for the [111] (Fig. 15) and [001] (Fig. 16) indented orientation. Finally, section 4-1-3 concerns the work-hardened polycrystalline nickel sample. The influence of the strain hardening modulus on pile-up orientation is analysed through the indentation imprint observation in the close [111] orientation (Fig. 17).

It is important to mention that the numerical simulations are controlled in displacement contrary to the experimental indentation. As a consequence, the maximum numerical indentation depths are imposed while it is not the case for the experimental ones. For a meaningful comparison, numerical and experimental residual topographies $Z(X, Y)$ are systematically normalized to the maximum indentation depths $h_{m}$.

\section{4-1-1 Electro-deposed polycrystalline nickel sample: a quasi-isotropic case}

This sample is a reference case. Indeed, the characteristic grain size is about $0.37 \mu \mathrm{m}$, which is small compared to the indentation depth (about $0.9 \mu \mathrm{m}$ ) and the lateral extension of the residual imprint (about $6.7 \mu \mathrm{m}$ ). Hence, the indentation tests involve a large number of grains and cannot be considered at the single crystal level. Fig. 12a-c display the AFM topography measurements. Pile-ups tend to evolve isotropically forming a circular pile-up distribution around the indentation imprints. The pile-up distribution is the same whatever the indenter orientation $\left(0^{\circ}, 60^{\circ}\right.$ and $\left.90^{\circ}\right)$. Fig. 12d-f presents the derivative of the three corresponding topographies. There is no evidence of dislocation slip lines emerging at the surface of the sample, suggesting that the majority of the plastic deformation occurs by relative nano-crystallite grain sliding (Delobelle et al., 2009). 

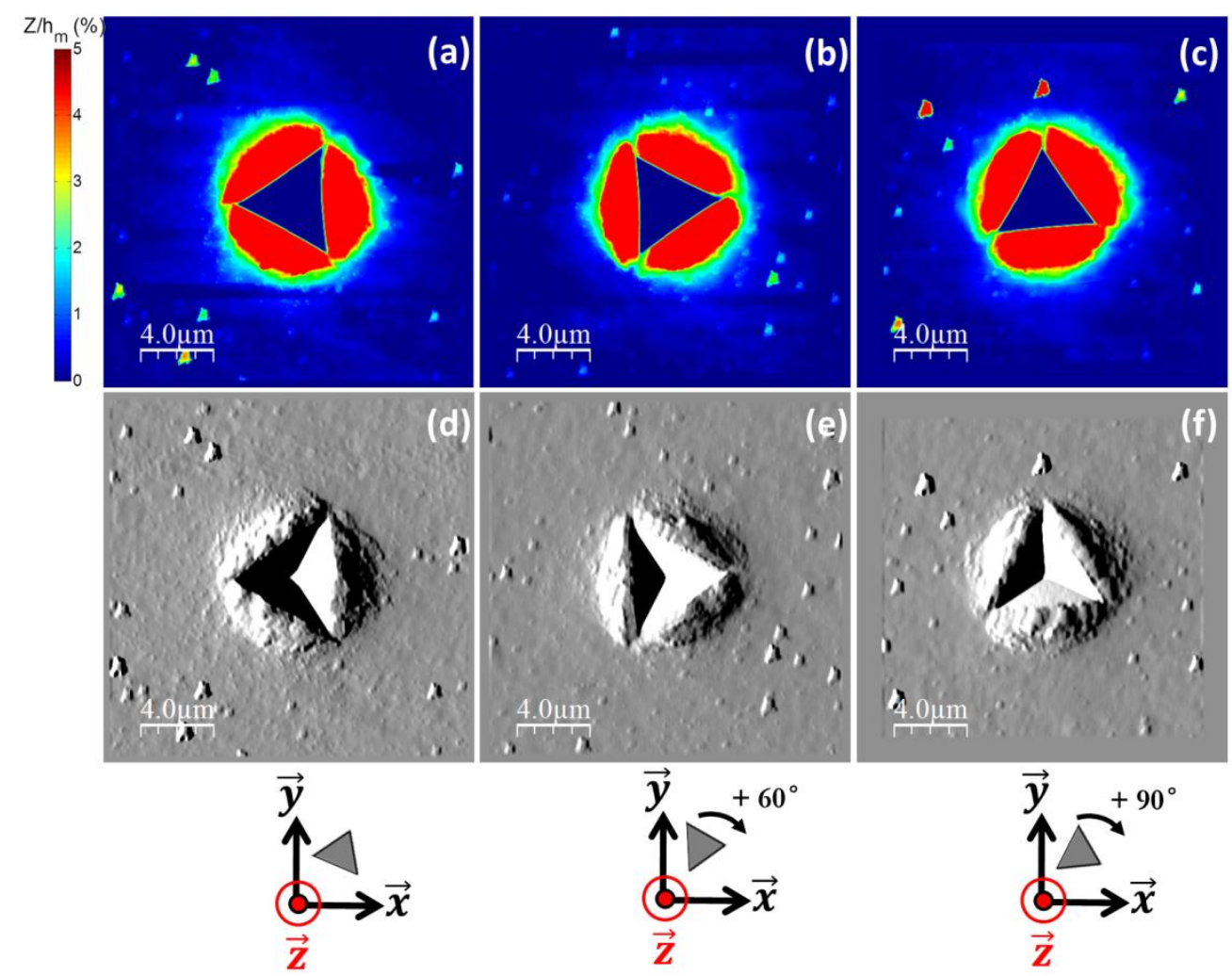

Fig. 12. AFM measurements performed on the electro-deposited sample: (a), (b) and (c) are topographic measurements with $0^{\circ}, 60^{\circ}$ and $90^{\circ}$ indenter orientations, respectively. (d), (e) and (f) are the corresponding derivative pictures.

\section{4-1-2 Annealed polycrystalline nickel sample}

Contrary to the previous sample, the annealed polycrystalline sample has large grains (mean diameter size of about $140 \mu \mathrm{m})$, compared to the maximum indentation depth $(0.9 \mu \mathrm{m})$. It can thus be assumed that the local material behaviour is not influenced by the neighbouring grains. Fig. 13a-c display AFM topographic measurements obtained for three indentation directions close to the [001], [101] and [111] crystallographic directions. 

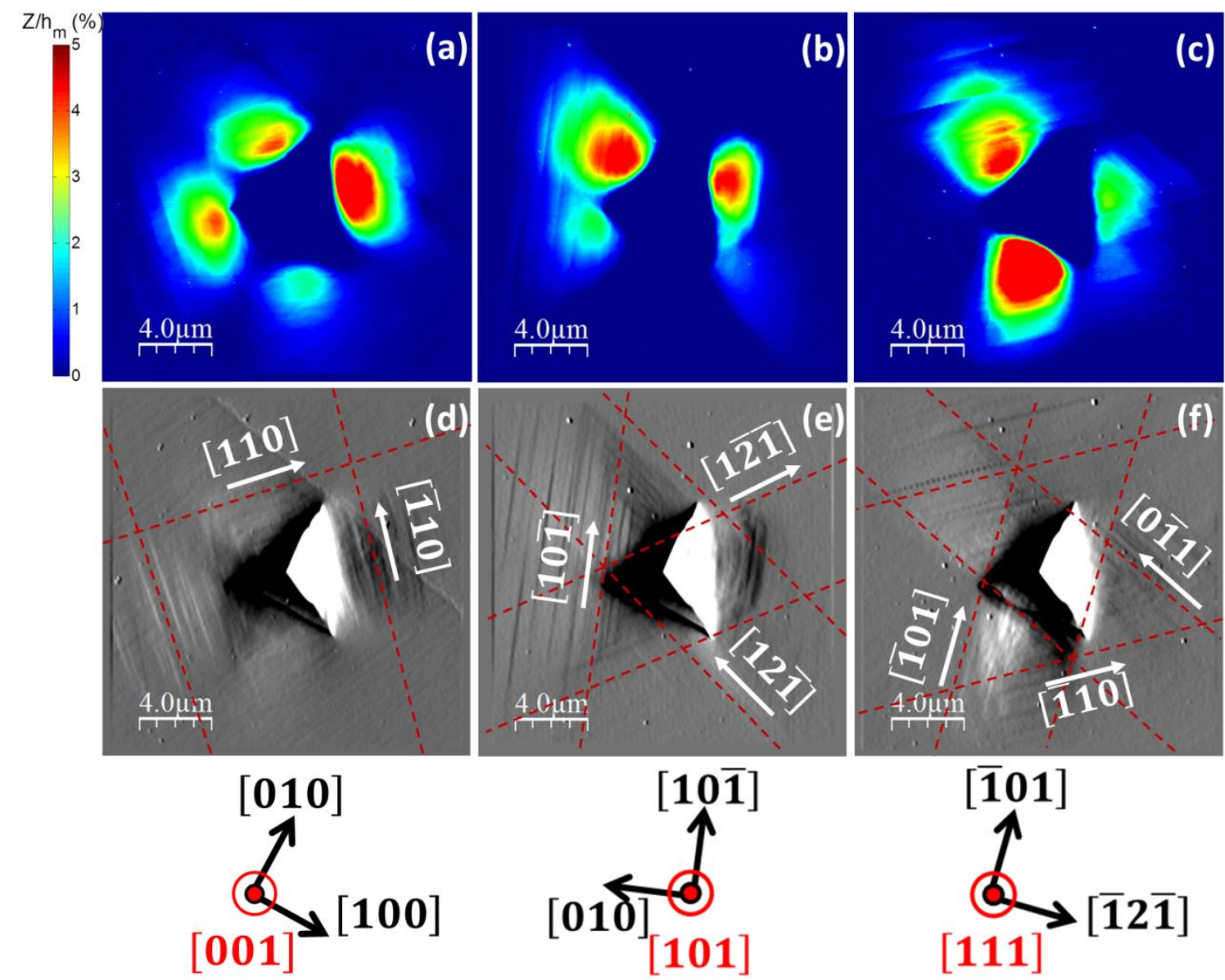

Fig. 13. AFM measurements performed on the annealed sample: (a), (b) and (c) are topographic measurements in the close [001], [101] and [111] crystallographic orientations, respectively. (d), (e) and (f) are the corresponding derivative pictures where slip traces are highlighted using red dashed lines.

The plastic anisotropy can easily be observed. Indeed, the grains close to the [001] and [101] directions present four pile-ups around the imprint (Fig. 13ab) whereas the grain close to the [111] direction shows only three (Fig. 13c). These observations are consistent with the previous experimental studies on FCC single crystals with Vickers (Holmes et al., 1993; Nibur and Bahr, 2003; Eidel, 2011), Berkovich (McElhaney et al., 1998), conical (Wang et al., 2004) and spherical indenters (Liu et al., 2008, 2005; Zambaldi et al., 2007). Moreover, pile-up sizes and distributions often show significant asymmetries, in height and lateral extension, depending on their orientations around the residual imprint. These asymmetries result from the convolution of the crystal slip system symmetry on the considered indented direction with the three-fold Berkovich indenter symmetry. Indeed, slip systems in the [001] indentation direction feature a four-fold symmetry, while those in the [101] indentation direction display a two-fold symmetry and a three-fold symmetry in the [111] indentation direction. Corresponding derivative measurements (Fig. 13d-f) reflect the slip system organisation through the slip traces at the sample surface. As expected (Van Groenou and Kadijk, 1989; Holmes et al., 1993; Farber et al., 1994; Nibur and Bahr, 2003), indenting along the [001] direction (Fig. 13d) 
make slip traces emerge on surface along the $\langle 101\rangle$ directions with a four-fold symmetry. The (101) indented grain shows slip lines with a two-fold symmetry in the $\langle 121\rangle$ directions and the $\langle 10 \overline{1}\rangle$ directions included in the (101) plane (Fig. 13e). Finally, the indentation on the (111) plane displays slip lines with a three-fold symmetry in the $\langle 110\rangle$ directions (Fig. 13f). Fig. 14 summarizes the slip systems activated in the three studied indentation directions.
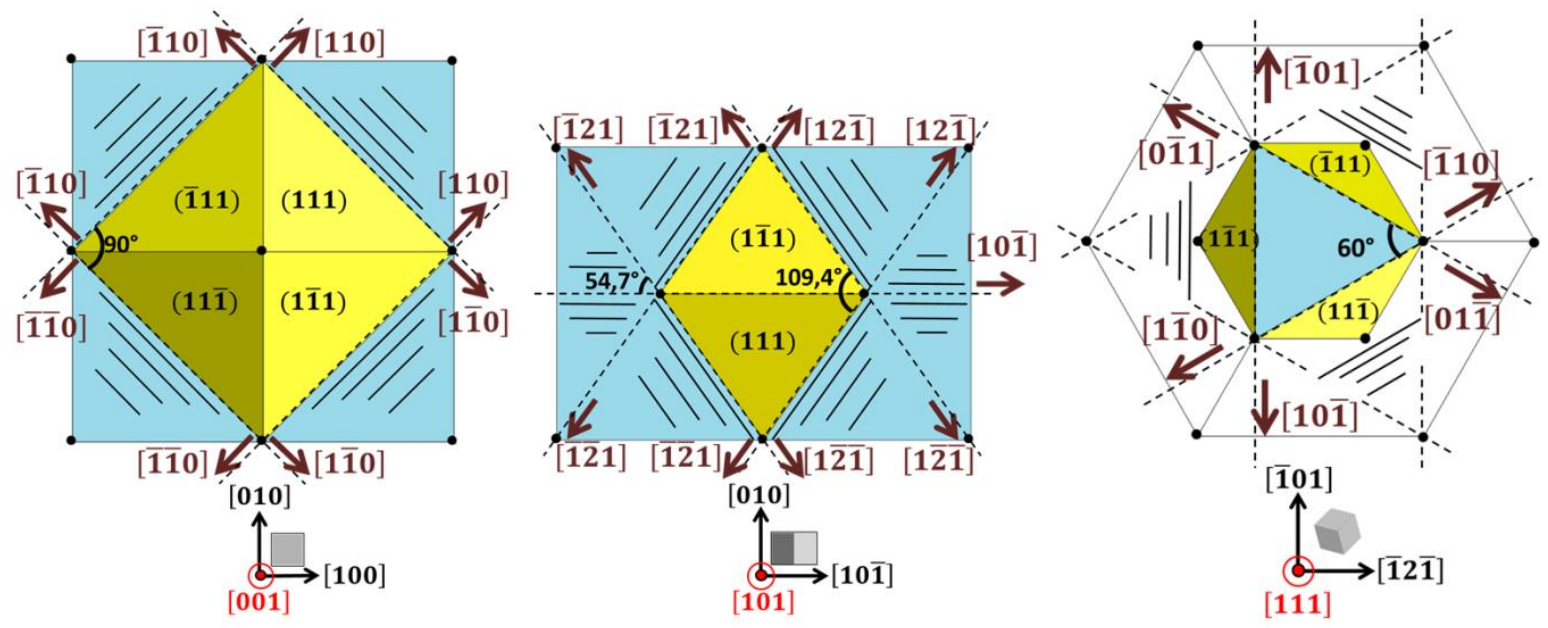

Fig. 14. Schemes of slip lines which should emerge on the surface after indentation in the [001], [101] and [111] crystallographic orientations.

The slip traces directions $[x, y, z]$ can be expressed as the set of all directions resulting from the intersection of the indented plane $(i, j, k)$ and the slip plane family $\{111\}$ :

$$
[x, y, z]=\{\{111\} \cap(i, j, k)\}
$$

Fig. 15 provides an example of the effect of the indenter disorientation $\left(60^{\circ}\right.$ and $\left.90^{\circ}\right)$ when indenting along the [111] direction. The pile-up distribution is largely dependent on the indenter orientation for a given indentation plane. The dislocations slip lines are contrarily rather insensitive to the indenter rotation (Fig. 15cd), their propagation direction is preserved and the only difference lies in the number of slip lines involved in each glide system. In fact, the Berkovich test imposes a complex stress field under the indenter in the material due to its particular geometry resulting in a non-uniform activation of slip systems around the indentation imprint, as shown in Fig. 10 and 11. 

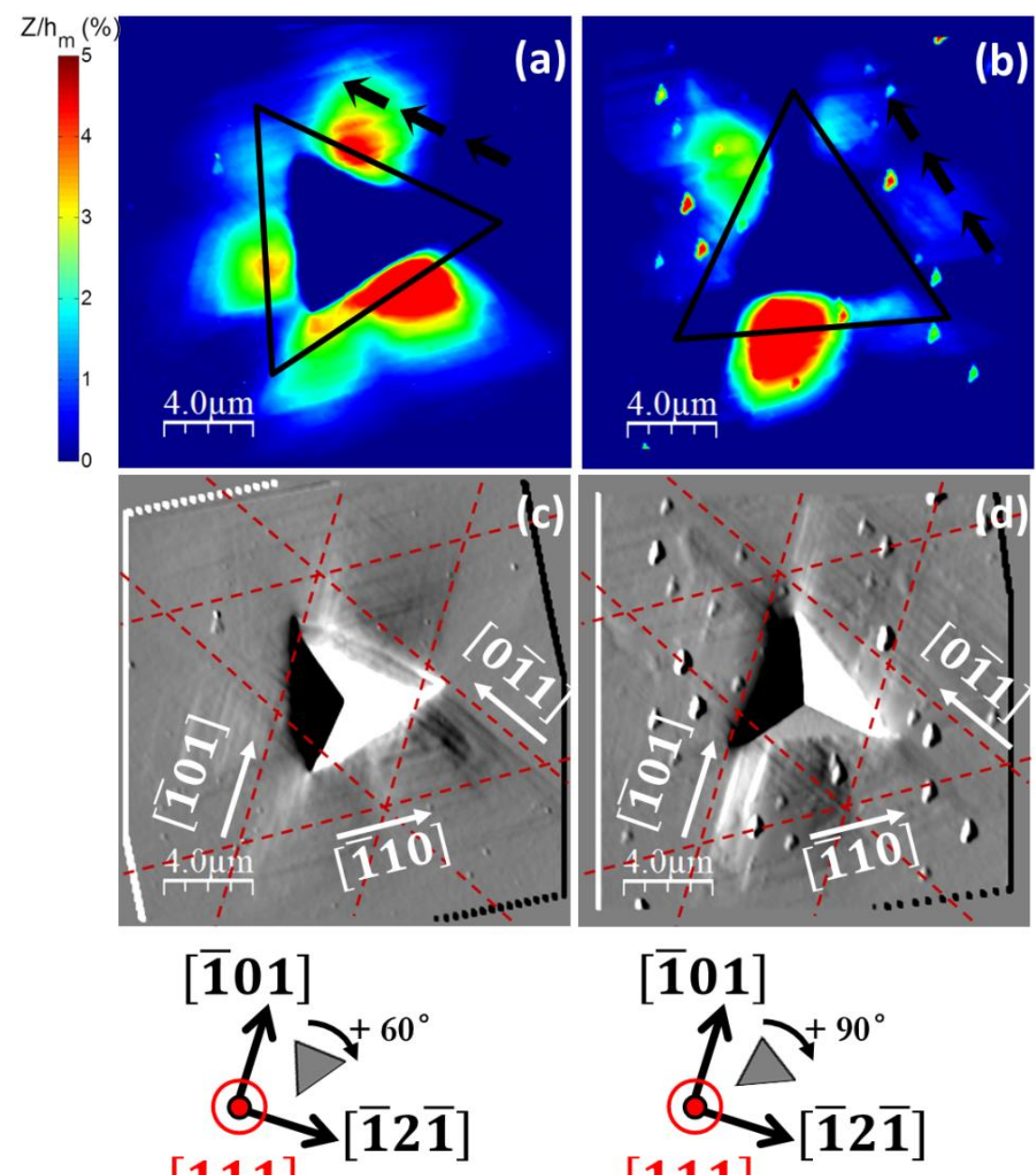

[111]
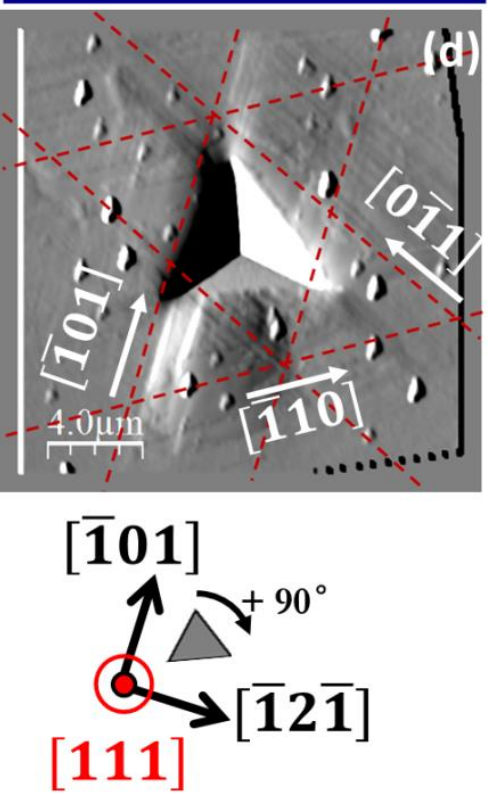

Fig. 15. AFM measurements performed on the annealed sample: (a) and (b) are topographic measurements in the close [111] crystallographic orientations with a $60^{\circ}$ and $90^{\circ}$ indenter disorientation, respectively. (c) and (d) are the corresponding derivative pictures where slip traces are highlighted using red dashed lines.

Fig. 16 shows the experimental and the numerical topographies for three indenter orientations: $0^{\circ}$ (Fig. 16ab), $30^{\circ}$ (Fig. 16cd) and 60 (Fig. 16ef) along the [001] axis. The material parameters have been calibrated using the procedure described in section 3-3 with the interaction matrix shown on the first line of the Table 2. This type of matrix is an independent hardening law introduced by Koiter with the general form $h^{s r}=h \delta^{s r}$ (Koiter, 1953), where $\delta^{s r}$ is the Kronecker symbol and, in our case, $h=100$. It means that the simulated material hardening is considered to feature self-hardening only. To make this analysis quantitative, experimental and numerical topographies along the same standard triangular path around the residual imprints are also presented in Fig. $16 \mathrm{~g}$-i for the three previous orientations. These profiles show that numerical and experimental pile-up height share the same order of magnitude but do not perfectly match.

The numerical pile-up distribution in Fig. 16b does not fit the experimental one (Fig 16a). As further shown in section 4-2, one of the error sources is the definition of the interaction matrix. 
Other authors obtained a better agreement under axisymmetric indentation using another type of interaction matrix: Zambaldi et al. (Zambaldi et al., 2007; Zambaldi and Raabe, 2010; Zambaldi et al., 2012, 2015) or Wang et al. (Wang et al., 2004) chose the interaction matrix components using a latent hardening law introduced by Asaro (Asaro and Needleman, 1985): $h^{s r}=h^{r} k^{s r}$, where $h^{r}$ is a constant or a function which decreases with shear strain, $k^{s r}=1$ if slip systems $s$ and $r$ are coplanar and $k^{s r}=1.4$ if they are not. Liu et al. (Liu et al., 2008, 2005) used a similar form of interaction matrix as in the present work but with non-zero values for latent components $\left(h_{1}=4, h_{2}=h_{3}=h_{4}=4.8, h_{5}=9, h_{6}=12\right)$. They all obtained simulated topographies showing four pile-up distribution for [001]-oriented grain. Zhang et al. (Zhang et al., 2015) and Chang et al. (Chang et al., 2010) have also shown that it is possible to reproduce the experimental topography using discrete dislocation dynamics simulation. Indeed, it will be shown in the section 4-2 that pile-ups are very sensitive to the interaction matrix components and particularly to the extra-diagonal terms. However, the pile-up distributions around the imprints are fairly well rendered, thus supporting the choice of the material's constitutive parameters deduced from the procedure in section 3-3. 


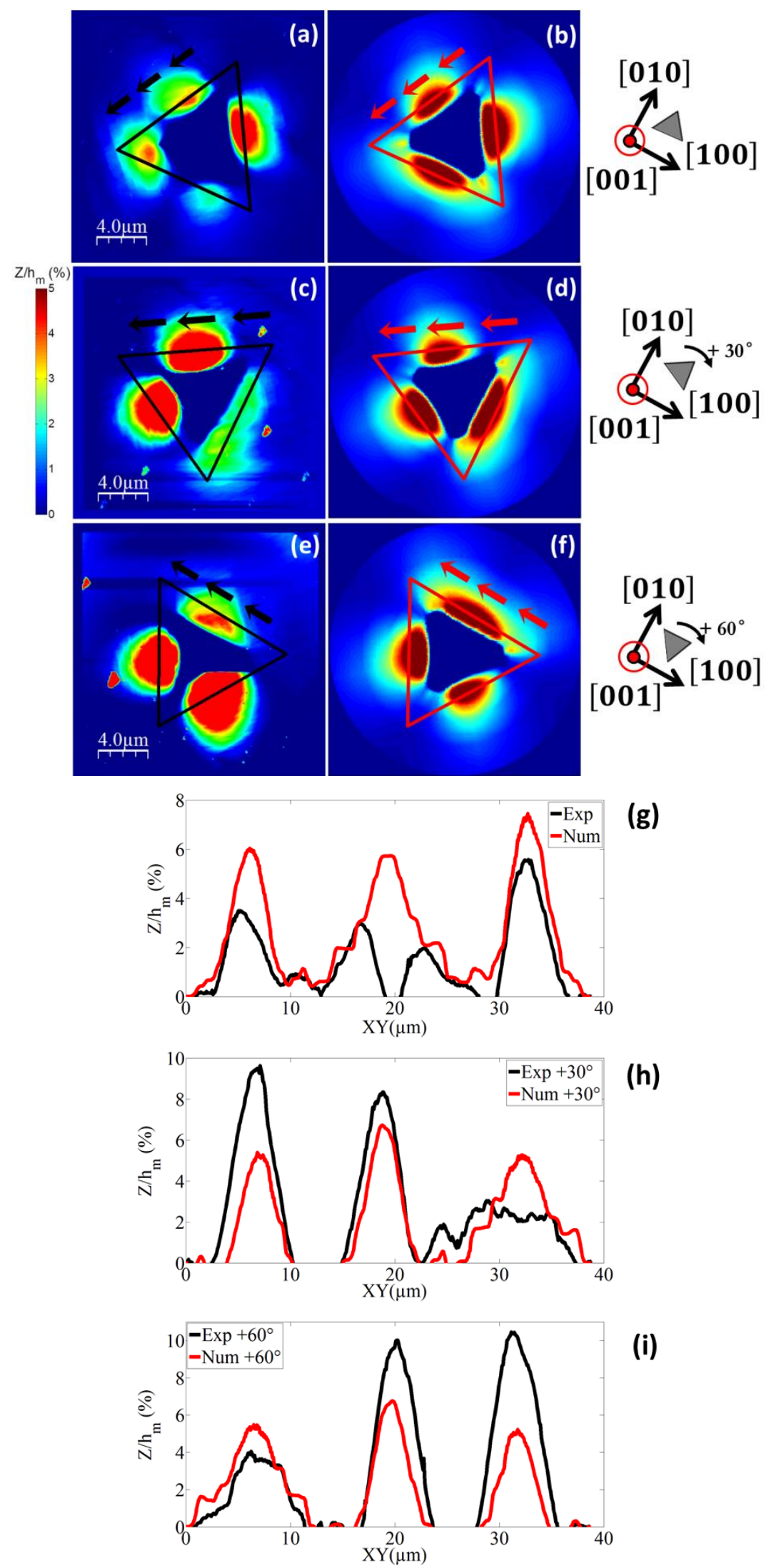

Fig. 16. Experimental (a, c, e) and numerical (b, d, f) topographies obtained for the [001] indentation direction on annealed sample and for three indenter rotations: $0^{\circ}, 30^{\circ}$ and $60^{\circ}$. Comparison of the pile-up profiles $(\mathrm{g}, \mathrm{h}, \mathrm{i}$ : experimental and numerical) along the same triangular path for the three previous indenter rotations. Hardening parameters used for simulating the virtual material: $q=1.3 \mathrm{MPa}, h_{1}=100, h_{i}=0$ (Table 2). 


\section{4-1-3 Work-hardened polycrystalline nickel sample: hardening effects}

As for the annealed sample, indentations performed on the work-hardened nickel sample result in significant pile-ups. The topographies of two residual imprints in the (111) plane obtained with an indenter orientation of $60^{\circ}$ and $90^{\circ}$ are presented in Fig. 17ab, and allow for a direct comparison with the results displayed on Fig. 15ab for the annealed sample. As previously mentioned pile-ups differ in heights and widths. On the work-hardened sample the sum of the pile-up heights around an imprint is about three times larger than that observed on the annealed one (Fig. 5). This is due to the plastic hardening modulus of the workhardened sample $(\approx 800 \mathrm{MPa})$ which is also about three times lower than the one for the annealed sample ( $\approx 2600 \mathrm{MPa}$ ) (Alcalá et al., 2000, 2008; Casals et al., 2007; Haddou, 2003; McElhaney et al., 1998). The pile-up distributions are also affected. Topographies on annealed sample present five and four pile-ups, respectively, whereas there are only three pile-ups around imprints on the cold-worked sample (Fig. 17ef). Indeed, on the cold-worked sample, pile-ups on each indenter side seem to be convoluted which results in a single larger pile-up on each indenter side. This is in agreement with Chang et al. results (Chang et al., 2010) which numerically show that increasing the value of the initial dislocation density can switch pile-up distribution around a conical impression performed on copper along the [111] indentation axis from a six- to a three-fold symmetry. This is in agreement with our observations as the total initial dislocation density of the tested material is of course greater for the work-hardened sample $\left(\sim 2.710^{14} \mathrm{~m} / \mathrm{m}^{3}\right)$ than for the annealed one $\left(\sim 3.210^{13} \mathrm{~m} / \mathrm{m}^{3}\right)$ (Alcalá et al., 2000; Haddou, 2003; Delobelle et al., 2009). Moreover, the plastic deformation on the cold-worked material is more localised closely the residual imprint. Pile-up lateral extension and propagation of dislocation slip lines actually remain confined in a plastic zone whose size does not exceed twice the size of the residual imprint (white dashed lines in Fig. 17cd). The size of this plastic zone can reach three to four times the size of the residual imprint in the case of the annealed sample.

As a conclusion and according to the literature, pile-up sizes and lateral extensions are a very good strain-hardening indicator. 

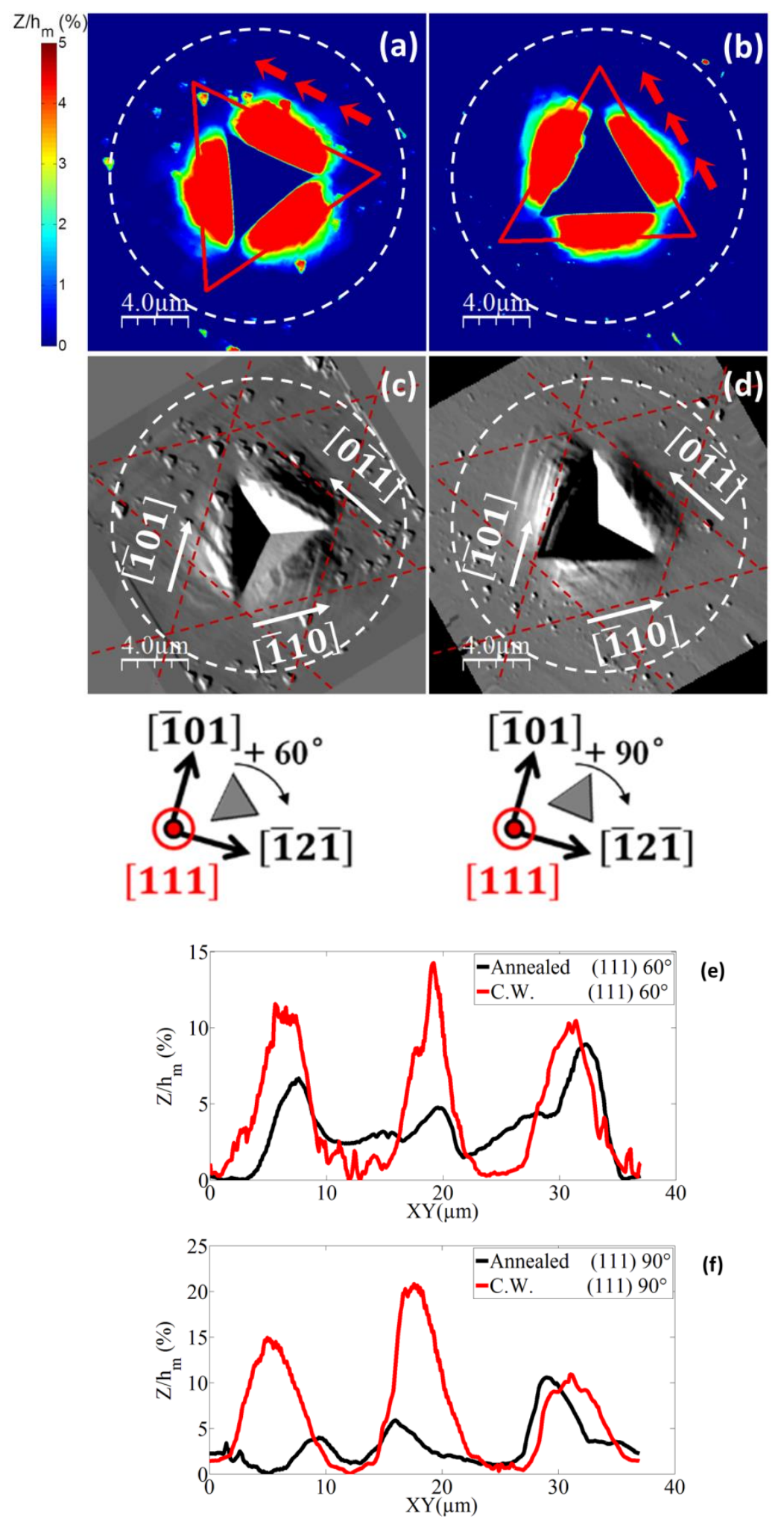

(e)

(f)

Fig. 17. AFM measurements performed on the work-hardened sample: (a), (b) are topographic measurements in the close [111] crystallographic orientations with a $60^{\circ}$ and $90^{\circ}$ indenter disorientation, respectively. (c), (d) are the corresponding derivative pictures where slip traces are highlighted using red dashed lines. The dashed white circles are drawn to show that pile-up lateral extension and propagation of dislocation slip lines remain confined in a plastic zone whose size does not exceed twice the size of the residual imprint. (e), (f): comparison of the pile-up profiles in the cold-worked and the annealed samples (see Figs. 15a and 15b) through the same triangular path. 


\section{4-2 Numerical sensitivity of the residual topography to the interaction matrix components}

The $12 \times 12$ hardening matrix $\overline{\bar{H}}$ has been used for weighting dislocation interactions on the different slip systems. It depends on six independent components. In this section, the sensitivity of the residual topography to the interaction matrix is probed for the annealed material. The exponential term in equation (13) tends to zero for large deformation so that:

$$
\left|\tau^{s}\right|=r_{0}+q \sum_{r=1}^{12} h^{s r}+K\left(\dot{\gamma}^{s}\right)^{1 / n}
$$

In addition, the interaction matrix symmetry imposes that $\sum h^{s r}$ is a constant value. For the sensitivity analysis, the $\sum h^{s r}$ value is arbitrary imposed to 100 . Six different virtual materials are built including the one defined in the section 3-3. Each of them promotes a particular interaction $h_{i}$ and is associated to a hardening matrix shown in Table 2. It is very important to note that each virtual material is defined in order to obtain the same macroscopic behaviour as the annealed nickel polycrystalline sample (Fig. 2).

First, to compare the slip activity, Fig. 18 shows a cross section obtained in the same condition as the Fig. 10 but for the fifth virtual material (the one promoting the $h_{5}$ glissile junction). And the same mechanical quantities are shown in the top view in Fig. 19. Although all the glide systems are all activated in the cases displayed on Fig. 10-11 and 18-19, it is clear that the interaction matrix definition deeply changes the plastic zone contour (total and on each slip system) and the cumulated strain in all the glide systems. Contrary to the self-hardening case, the plastic zone contours seem to be irregular and more angular. The difference between Fig. 11 and 19, particularly for the total cumulated strain, is clearly highlighted. However this kind of information still not allows a direct comparison with the experimental behaviour. 




Fig. 18. Details of a (001) Berkovich indentation plastic zone obtained on a (010) cross section: the total cumulated plastic strain (at the centre of the figure), and the ones obtained on the 12 slip systems at the maximum indentation depth (with transparent indenter). Hardening parameters used for simulating the virtual material: $q=10 \mathrm{MPa}, h_{5}=23, h_{i}=1$ (Table 2). 

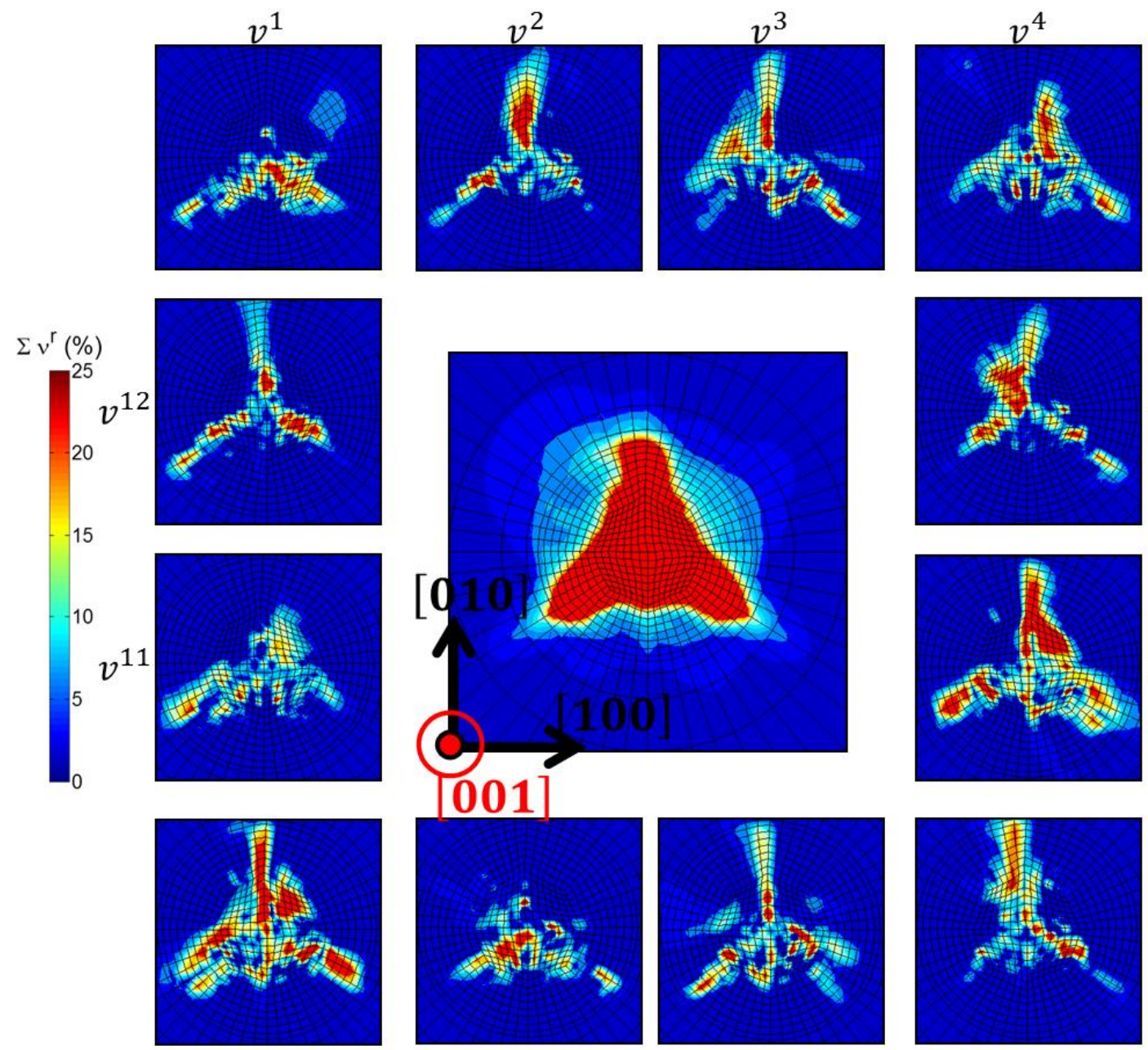

$$
v^{10}
$$

$$
v^{9}
$$

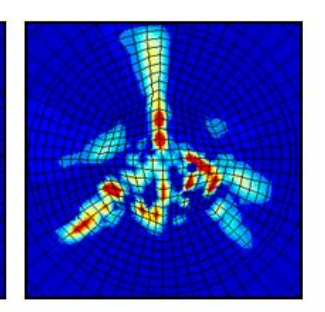

$v^{8}$
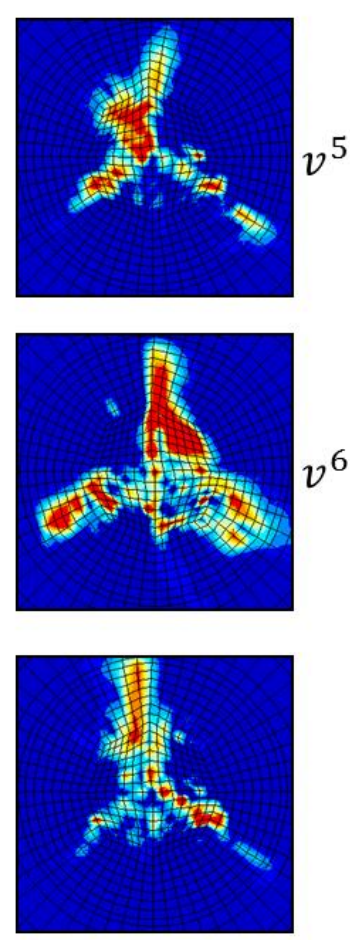

$v^{7}$

Fig. 19. Details of a (001) Berkovich indentation plastic zone obtained in the top view: the total cumulated plastic strain (at the centre of the figure), and the ones obtained on the 12 slip systems at the maximum indentation depth. Hardening parameters used for simulating the virtual material: $q=10 \mathrm{MPa}, h_{5}=23, h_{i}=1$ (Table 2).

Then, the numerical topographies obtained by indentation of the six different virtual materials, along the same triangular path and for the [001] direction are shown in Fig. 20. The first observation is that the activation of a different interaction component is sufficient to completely change the pile-up distribution around the residual imprint. It seems that the activation of the latent hardening terms strongly affects the pile-up distribution obtained numerically, as for the cumulated strain contours shown in Fig. 11 and 19. In particular some materials (namely, those enhancing $h_{2}, h_{3}, h_{4}$ and $h_{5}$ ) now exhibit the four pile-up distribution observed experimentally (Fig. 16a). Indeed, it seems necessary to activate the latent hardening to observe four pile-ups for the [001] direction. 

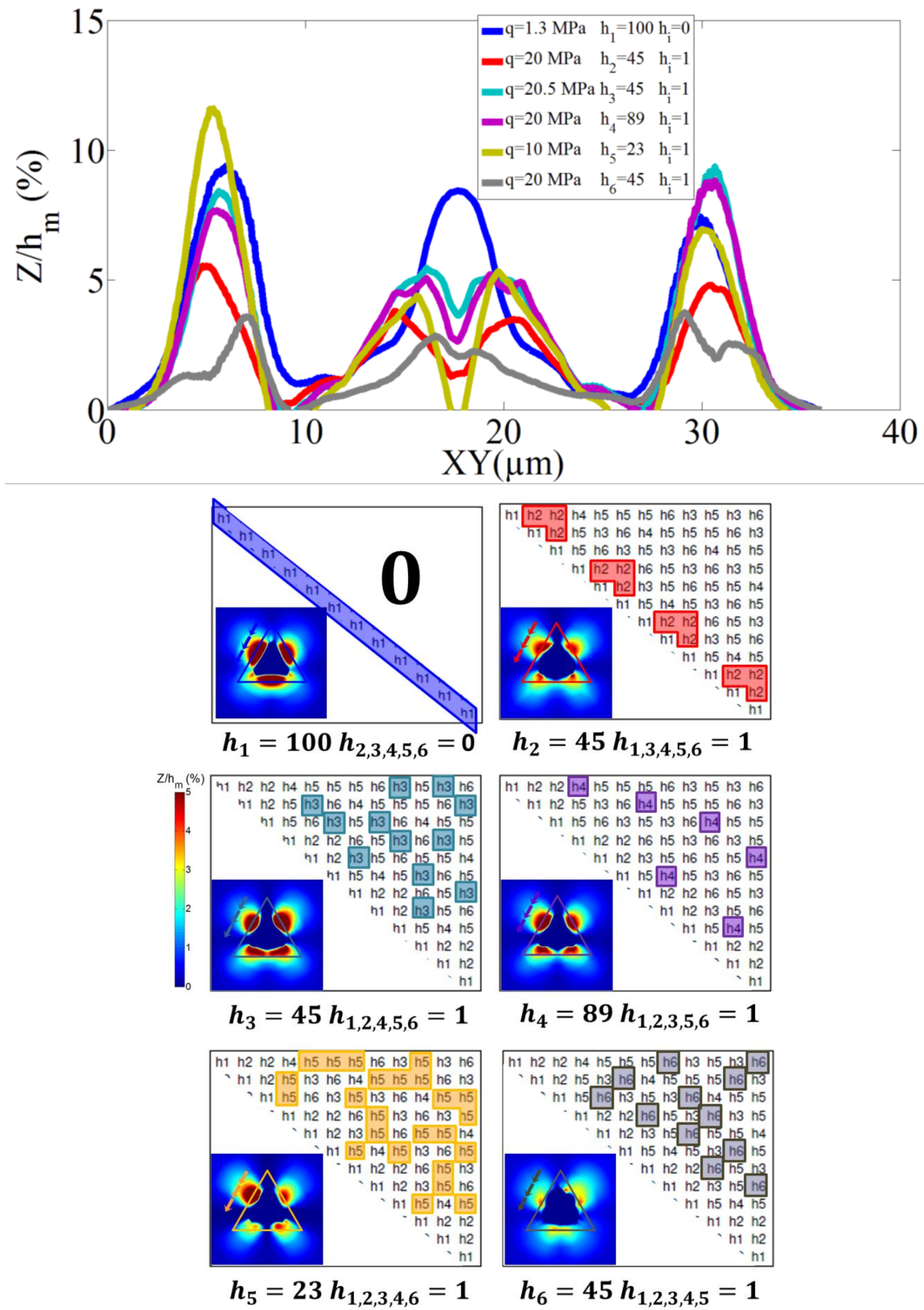

Fig. 20. Numerical pile-up profiles sensitivity to the components of the interaction matrix. The values of the different parameters used for the simulations have been listed in the different figures. The set of simulations corresponds to a [001] indentation direction. 
Moreover, it seems clear that pile-up sizes are affected by the choice of the interaction matrix components. Indeed, significant differences in pile-up heights are observed in Fig. 20. In the case where Lomer locks $\left(h_{6}\right)$ dominate, the pile-up heights are smaller than in the case where the activated slip system interactions are mainly coplanar $\left(h_{2}\right)$, collinear $\left(h_{4}\right)$ or present mainly Hirth locks $\left(h_{3}\right)$ and glissile junctions $\left(h_{5}\right)$. It is to be noted that when the change in the interaction matrix affects the pile-up profiles, the impact on pile-up heights is not proportional along the entire standard triangular path. Indeed, by adjusting the interaction matrix, it is possible to promote the height of one pile-up instead of the others. These results reveal the nature of some non-linear dependence of pile-up distribution to the interaction matrix components.

Finally, the values of the hardening rate and the components of the matrix defining the interactions between slip systems appear to be essential and control the pile-up patterns (size, shape, distribution). Therefore, an inverse finite element method from a Berkovich nanoindentation experiment (residual topography, indentation curve), appears to be a possible way to extract some of the material constitutive parameters involved in the Meric-Cailletaud's model. Above all, there may be enough information in topography measurements on different crystallographic orientations to estimate some components of the interaction matrix.

\section{5- Conclusions}

In this paper a study of the anisotropy and the plasticity properties of polycrystalline nickel under nanoindentation at a single crystal scale has been presented. Pile-ups and slip traces are systematically analysed for indentations performed in different crystallographic directions and with different orientations of the Berkovich indenter in a given indentation plane. The following conclusions can be drawn:

- The sensitivity of the pile-up heights around imprints to the indentation depth depends on the grain orientations and on the state of the material through its work-hardening modulus.

- The impact of pile-up dimensions on the evaluation of indentation modulus and hardness has been evaluated. In the case of the work-hardened sample, the overestimation of hardness and indentation modulus can reach about 20 and $10 \%$, respectively, underlining the importance of the real projected contact area due to pile-up formation which is not often, if ever, taken into account. It encourages to properly analyse the information collected by postimaging and having critical mind against automatically generated values.

- Based on a single stress-strain tensile curve obtained experimentally and numerically by the integration of single crystal plasticity constitutive equations in tensile conditions for four 
different crystallographic orientations, we have proposed as a first approach a way to link macroscopic and microscopic set of material's parameters for annealed and cold-worked nickel samples. The resulting parameters have been validated comparing the experimental tensile curve and the one obtained by FEM on a polycrystal composed of 91 randomly-oriented grains.

- Pile-up distribution experimentally observed around residual imprint of indentation is strongly related to the indented crystallographic orientation and to the Berkovich indenter orientation in a given indented plane. Moreover, hardening rate appears to play a crucial role on the pile-up dimensions.

- A numerical modelling of the nanoindentation test has been implemented in a finite element code. The parameters of the single crystal plasticity material model previously identified have been introduced. Numerical simulation results are, at least for two of the three tested orientations, in a good agreement with the experimental observations: pile-ups are distributed in the same way. Moreover, pile-up heights and widths share the same order of magnitude.

Finally, the values of the hardening rate and the components of the matrix defining the interactions between slip systems appear to be essential and control the pile-up patterns (size, shape, distribution). As an example, it seems necessary to activate the latent hardening components to observe four pile-ups for a Berkovich indentation along the [001] direction. Therefore, an inverse finite element method from a Berkovich nanoindentation experiment (residual topography, indentation curve), appears to be a possible way to extract some of the material's constitutive parameters involved in the Meric-Cailletaud's model. Above all, there may be enough information in measures topographies to estimate some components of the interaction matrix.

\section{Acknowledgements}

The authors express their gratitude to Vladislav A. Yastrebov (CNRS Research Scientist at Centre des Matériaux, MINES ParisTech.) and all members of the Zebulon's valorisation team for their assistance. 


\section{References}

Alcalá, J., Barone, A.C., Anglada, M., 2000. The influence of plastic hardening on surface deformation modes around Vickers and spherical indents. Acta Mater. 48, 3451-3464.

Alcalá, J., Casals, O., Očenášek, J., 2008. Micromechanics of pyramidal indentation in fcc metals: Single crystal plasticity finite element analysis. J. Mech. Phys. Solids 56, 3277-3303.

Asaro, R.J., Needleman, A., 1985. Texture development and strain hardening in rate dependent polycrystals. Acta Met. 33, 923-953.

Askari, H., Maughan, M.R., Abdolrahim, N., Sagapuram, D., Bahr, D.F., Zbib, H.M., 2015. A stochastic crystal plasticity framework for deformation of micro-scale polycrystalline materials. Int. J. Plast. 68, 21-33.

Bassani, J.L., Wu, T.-Y., 1991. Latent Hardening in Single Crystals II. Analytical Characterization and Predictions. Proc. R. Soc. Lond. Ser. Math. Phys. Sci. 435, 21-41.

Bishop, J.F.W., Hill, R., 1951a. CXXVIII. A theoretical derivation of the plastic properties of a polycrystalline face-centred metal. Lond. Edinb. Dublin Philos. Mag. J. Sci. 42, 1298-1307.

Bishop, J.F.W., Hill, R., 1951b. XLVI. A theory of the plastic distortion of a polycrystalline aggregate under combined stresses. Lond. Edinb. Dublin Philos. Mag. J. Sci. 42, 414-427.

Bittencourt, E., 2012. Numerical solution of crystal plasticity problems by a mixed formulation. Comput. Mater. Sci. 63, 145-153.

Bocciarelli, M., Bolzon, G., 2009. Indentation and imprint mapping for the identification of interface properties in film-substrate systems. Int. J. Fract. 155, 1-17.

Bocciarelli, M., Bolzon, G., Maier, G., 2008. A constitutive model of metal-ceramic functionally graded material behavior: Formulation and parameter identification. Comput. Mater. Sci. 43, 16-26.

Bocciarelli, M., Bolzon, G., Maier, G., 2005. Parameter identification in anisotropic elastoplasticity by indentation and imprint mapping. Mech. Mater. 37, 855-868.

Bolzon, G., Bocciarelli, M., Chiarullo, E.J., 2009. Mechanical characterization of materials by microindentation and AFM scanning, in: Applied Scanning Probe Methods XII. Springer, pp. 85-120.

Bolzon, G., Maier, G., Panico, M., 2004. Material model calibration by indentation, imprint mapping and inverse analysis. Int. J. Solids Struct. 41, 2957-2975.

Bolzon, G., Molinas, B., Talassi, M., 2012. Mechanical Characterisation of Metals by Indentation Tests: An Experimental Verification Study for On-site Applications: Strain 48, 517-527.

Cailletaud, G., 2009. Une introduction à la plasticité cristalline interactions avec l'environnement. EDP Sciences, pp. 81-115.

Casals, O., Forest, S., 2009. Finite element crystal plasticity analysis of spherical indentation in bulk single crystals and coatings. Proc. 17th Int. Workshop Comput. Mech. Mater. IWCMM-17 45, 774-782.

Casals, O., Očenášek, J., Alcalá, J., 2007. Crystal plasticity finite element simulations of pyramidal indentation in copper single crystals. Acta Mater. 55, 55-68. 
Chang, H.-J., Fivel, M., Rodney, D., Verdier, M., 2010. Multiscale modelling of indentation in FCC metals: From atomic to continuum. Comput. Metall. Scale Transit. Métallurgie Numér. Chang. Déchelle 11, 285-292.

Dahlberg, C.F.O., Saito, Y., Öztop, M.S., Kysar, J.W., 2014. Geometrically necessary dislocation density measurements associated with different angles of indentations. Int. J. Plast. 54, 81-95.

Dao, M., Chollacoop, N., Vliet, K.J.V., Venkatesh, T.A., Suresh, S., 2001. Computational modeling of the forward and reverse problems in instrumented sharp indentation. Acta Mater. 49, $3899-$ 3918.

Delobelle, P., Dali, S., Richard, F., 2011. Interprétation du module d'indentation dans le cas des matériaux anisotropes et/ou actifs. Matér. Tech. 99, 185-196.

Delobelle, P., Richard, F., Qasmi, M., 2009. Quelques potentialités de l'essai de nanoindentation. Cas du nickel polycristallin et électrodéposé : interprétation du module d'indentation, de la dureté, des effets d'échelle et des paramètres d'identification inverse. Matér. Tech. 96, 83-94.

Eidel, B., 2011. Crystal plasticity finite-element analysis versus experimental results of pyramidal indentation into (l 0 1) fcc single crystal. Acta Mater. 59, 1761-1771.

Eidel, B., Gruttmann, F., 2007. Squaring the circle - A curious phenomenon of fcc single crystals in spherical microindentation. Proc. 15th Int. Workshop Comput. Mech. Mater. 15th Int. Workshop Comput. Mech. Mater. 39, 172-178.

Farber, B.Y., Chiarelli, A.S., Heuer, A.H., 1994. A dislocation mechanism of crack nucleation in cubic zirconia single crystals. Philos. Mag. A 70, 201-217.

Fivel, M., 2004. Plasticite Cristalline Et Transition D'echelle Cas Du Monocristal. Ed. Techniques Ingénieur.

Fivel, M., Robertson, C., Canova, G., Boulanger, L., 1998. Three-dimensional modeling of indentinduced plastic zone at a mesoscale. Acta Mater. 46, 6183-6194.

Francavilla, A., Zienkiewicz, O.C., 1975. A note on numerical computation of elastic contact problems. Int. J. Numer. Methods Eng. 9, 913-924.

Franciosi, P., 1985. The concepts of latent hardening and strain hardening in metallic single crystals. Acta Metall. 33, 1601-1612.

Gale, J.D., Achuthan, A., 2014. The effect of work-hardening and pile-up on nanoindentation measurements. J. Mater. Sci. 49, 5066-5075.

Haddou, H., 2003. Influence de la taille de grain et de l'énergie de défaut d'empilement sur l'état de contraintes internes développé au cours de la déformation plastique en traction simple et en fatigue oligocyclique (Alliages CFC). Compiègne.

Holmes, D., Heuer, A.H., Pirouz, P., 1993. Dislocation structures around Vickers indents in $9.4 \mathrm{~mol} \%$ Y2O3-stabilized cubic ZrO2 single crystals. Philos. Mag. A 67, 325-342.

Horcas, I., Fernández, R., Gómez-Rodríguez, J.M., Colchero, J., Gómez-Herrero, J., Baro, A.M., 2007. WSXM: A software for scanning probe microscopy and a tool for nanotechnology. Rev. Sci. Instrum. 78, 013705. 
Jean, M., 1995. Frictional contact in collections of rigid or deformable bodies: numerical simulation of geomaterial motions. Mech. Geomaterial Interfaces 463.

Kese, K., Li, Z.C., 2006. Semi-ellipse method for accounting for the pile-up contact area during nanoindentation with the Berkovich indenter. Scr. Mater. 55, 699-702.

Kese, K.O., Li, Z.C., Bergman, B., 2005. Method to account for true contact area in soda-lime glass during nanoindentation with the Berkovich tip. Mater. Sci. Eng. A 404, 1-8.

Koiter, W.T., 1953. Stress-strain relations, uniqueness and variational theorems for elastic-plastic materials with a singular yield surface. Quart Appl Math 11, 350-354.

Kucharski, S., Stupkiewicz, S., Petryk, H., 2014. Surface Pile-Up Patterns in Indentation Testing of Cu Single Crystals. Exp. Mech. 54, 957-969.

Lee, W.B., Chen, Y.P., 2010. Simulation of micro-indentation hardness of FCC single crystals by mechanism-based strain gradient crystal plasticity. Int. J. Plast. 26, 1527-1540.

Liu, Y., Varghese, S., Ma, J., Yoshino, M., Lu, H., Komanduri, R., 2008. Orientation effects in nanoindentation of single crystal copper. Int. J. Plast. 24, 1990-2015.

Liu, Y., Wang, B., Yoshino, M., Roy, S., Lu, H., Komanduri, R., 2005. Combined numerical simulation and nanoindentation for determining mechanical properties of single crystal copper at mesoscale. J. Mech. Phys. Solids 53, 2718-2741.

McElhaney, K.W., Vlassak, J.J., Nix, W.D., 1998. Determination of indenter tip geometry and indentation contact area for depth-sensing indentation experiments. J. Mater. Res. 13, 13001306.

Méric, L., Cailletaud, G., 1991. Single crystal modeling for structural calculations: Part 2-finite element implementation. J. Eng. Mater. Technol. 113, 171-182.

Méric, L., Cailletaud, G., Gaspérini, M., 1994. FE calculations of copper bicrystal specimens submitted to tension-compression tests. Acta Metall. Mater. 42, 921-935.

Méric, L., Poubanne, P., Cailletaud, G., 1991. Single crystal modeling for structural calculations: part 1-model presentation. J. Eng. Mater. Technol. 113, 162-170.

Moy, C.K.S., Bocciarelli, M., Ringer, S.P., Ranzi, G., 2011. Identification of the material properties of Al 2024 alloy by means of inverse analysis and indentation tests. Mater. Sci. Eng. A 529, 119-130.

Nibur, K.A., Bahr, D.F., 2003. Identifying slip systems around indentations in FCC metals. Scr. Mater. 49, 1055-1060.

Oliver, W.C., Pharr, G.M., 2004. Measurement of hardness and elastic modulus by instrumented indentation: Advances in understanding and refinements to methodology. J. Mater. Res.PITTSBURGH THEN WARRENDALE- 19, 3-20.

Oliver, W.C., Pharr, G.M., 1992. An improved technique for determining hardness and elastic modulus using load and displacement sensing indentation experiments. J. Mater. Res. 7, 1564-1583. 
Quey, R., Dawson, P.R., Barbe, F., 2011. Large-scale 3D random polycrystals for the finite element method: Generation, meshing and remeshing. Comput. Methods Appl. Mech. Eng. 200, 17291745 .

Rao, J.G., Varma, S.K., 1993. The effect of grain size and strain rate on the. Metall. Trans. A 24, 25592568.

Rauchs, G., Bardon, J., 2011. Identification of elasto-viscoplastic material parameters by indentation testing and combined finite element modelling and numerical optimization. Finite Elem. Anal. Des. 47, 653-667.

Sabnis, P.A., Forest, S., Arakere, N.K., Yastrebov, V.A., 2013. Crystal plasticity analysis of cylindrical indentation on a Ni-base single crystal superalloy. Int. J. Plast. 51, 200-217.

Sachdeva, T.D., Ramakrishnan, C.V., 1981. A finite element solution for the two-dimensional elastic contact problems with friction. Int. J. Numer. Methods Eng. 17, 1257-1271.

Schmid, E., Boas, W., 1935. Kristall plastzitat. Springer Verlag.

Taljat, B., Zacharia, T., Kosel, F., 1998. New analytical procedure to determine stress-strain curve from spherical indentation data. Int. J. Solids Struct. 35, 4411-4426.

Tasan, C.C., Diehl, M., Yan, D., Zambaldi, C., Shanthraj, P., Roters, F., Raabe, D., 2014a. Integrated experimental-simulation analysis of stress and strain partitioning in multiphase alloys. Acta Mater. 81, 386-400.

Tasan, C.C., Hoefnagels, J.P.M., Diehl, M., Yan, D., Roters, F., Raabe, D., 2014b. Strain localization and damage in dual phase steels investigated by coupled in-situ deformation experiments and crystal plasticity simulations. Int. J. Plast. 63, 198-210.

Van Groenou, A.B., Kadijk, S.E., 1989. Slip patterns made by sphere indentations on single crystal MnZn ferrite. Acta Metall. 37, 2613-2624.

Vlassak, J.J., Nix, W.D., 1994. Measuring the elastic properties of anisotropic materials by means of indentation experiments. J. Mech. Phys. Solids 42, 1223-1245.

Vlassak, J.J., Nix, W.D., 1993. Indentation modulus of elastically anisotropic half spaces. Philos. Mag. A 67, 1045-1056.

Wang, Y., Raabe, D., Klüber, C., Roters, F., 2004. Orientation dependence of nanoindentation pile-up patterns and of nanoindentation microtextures in copper single crystals. Acta Mater. 52, 22292238.

Wronski, M., 1994. Couplage du contact et du frottement avec la mécanique non linéaire des solides en grandes déformations. Application à l'étude des blocs de mousse en polyuréthane.

Wu, T.-Y., Bassani, J.L., Laird, C., 1991. Latent Hardening in Single Crystals I. Theory and Experiments. Proc. R. Soc. Lond. Ser. Math. Phys. Sci. 435, 1-19.

Yao, W.Z., Krill, C.E., Albinski, B., Schneider, H.-C., You, J.H., 2014. Plastic material parameters and plastic anisotropy of tungsten single crystal: a spherical micro-indentation study. J. Mater. Sci. 49, 3705-3715. 
Zaafarani, N., Raabe, D., Singh, R.N., Roters, F., Zaefferer, S., 2006. Three-dimensional investigation of the texture and microstructure below a nanoindent in a Cu single crystal using 3D EBSD and crystal plasticity finite element simulations. Acta Mater. 54, 1863-1876.

Zamanzade, M., Vehoff, H., Barnoush, A., 2013. Effect of chromium on elastic and plastic deformation of Fe3Al intermetallics. Intermetallics 41, 28-34.

Zambaldi, C., Raabe, D., 2010. Plastic anisotropy of $\mathrm{\gamma}$-TiAl revealed by axisymmetric indentation. Acta Mater. 58, 3516-3530.

Zambaldi, C., Roters, F., Raabe, D., Glatzel, U., 2007. Modeling and experiments on the indentation deformation and recrystallization of a single-crystal nickel-base superalloy. Mater. Sci. Eng. A 454-455, 433-440.

Zambaldi, C., Yang, Y., Bieler, T.R., Raabe, D., 2012. Orientation informed nanoindentation of $\alpha$ titanium: Indentation pileup in hexagonal metals deforming by prismatic slip. J. Mater. Res. 27, 356-367.

Zambaldi, C., Zehnder, C., Raabe, D., 2015. Orientation dependent deformation by slip and twinning in magnesium during single crystal indentation. Acta Mater. 91, 267-288.

Zhang, J. -I., Zaefferer, S., Raabe, D., 2015. A study on the geometry of dislocation patterns in the surrounding of nanoindents in a TWIP steel using electron channeling contrast imaging and discrete dislocation dynamics simulations. Mater. Sci. Eng. A 636, 231-242. 


\section{Table caption}

Table 1. Notation for the FCC slip systems according to Schmid \& Boas convention (Schmid and Boas, 1935).

Table 2. Material parameters calibration for the annealed sample using the procedure in section 3-3. 


\section{Figures captions}

Fig. 1. EBSD measurements of the studied areas on the three polycrystalline nickel samples: (a) electro-deposed sample, (b) annealed sample, (c) 30\% work-hardened sample.

Fig. 2. Macroscopic true stress-true strain tensile curve of the polycrystalline annealed nickel sample (blue curve); Exponential isotropic hardening law used to model the response (Eq.14,red curve); Numerical true stress-true strain tensile curve of the polycrystalline representative elementary volume composed of 91 randomly oriented grains (Eqs.7 to 12, black curve).

Fig. 3. Typical examples of load-depth curves for the three studied samples: electro-deposited, annealed and cold-worked samples.

Fig. 4. Approximation of the real projected contact area resulting from pile-up formation: width $w_{i}$ and height $a_{i}$ of each pile-up around the imprint are considered to determine the projected area using triangles. Example on the electro-deposited nickel sample (quasi-isotropic material).

Fig. 5. Sum of the pile-up heights as a function of the indentation depths for different grain orientations. Cases of annealed and cold-worked specimens.

Fig. 6. Indentation modulus (a) and hardness (b) values without and with pile-up corrections as a function of the grain orientations for electro-deposited, annealed and work-hardened samples. [ $\left.{ }^{\star}\right]$ closed-forms proposed by Vlassak \& Nix (Vlassak and Nix, 1993, 1994) and Delobelle et al. (Delobelle et al., 2009, 2011).

Fig. 7. Mesh used in the finite element simulations (cross sectional view).

Fig. 8. Finite element tensile test modelling: polycrystalline representative elementary volume composed of 91 randomly oriented grains.

Fig. 9. Flow chart summarizing the identification procedure used to determine the material plastic parameters in the nanoindentation model.

Fig. 10. Details of a (001) Berkovich indentation plastic zone obtained on a (010) cross section (same as in Fig. 7): the total cumulated plastic strain (at the centre of the figure), and the ones 
obtained on the 12 slip systems at the maximum indentation depth (with transparent indenter). Hardening parameters used for simulating the virtual material: $q=1.3 \mathrm{MPa}, h_{1}=100, h_{i}=0$ (Table 2).

Fig. 11. Details of a (001) Berkovich indentation plastic zone obtained in the top view: the total cumulated plastic strain (at the centre of the figure), and the ones obtained on the 12 slip systems at the maximum indentation depth. Hardening parameters used for simulating the virtual material: $q=1.3 \mathrm{MPa}, h_{1}=100, h_{i}=0$ (Table 2).

Fig. 12. AFM measurements performed on the electro-deposited sample: (a), (b) and (c) are topographic measurements with a $0^{\circ}, 60^{\circ}$ and $90^{\circ}$ indenter orientations, respectively. (d), (e) and (f) are the corresponding derivative pictures.

Fig. 13. AFM measurements performed on the annealed sample: (a), (b) and (c) are topographic measurements in the close [001], [101] and [111] crystallographic orientations, respectively. (d), (e) and (f) are the corresponding derivative pictures where slip traces are highlighted using red dashed lines.

Fig. 14. Schemes of slip lines which should emerge on the surface after indentation in the [001], [101] and [111] crystallographic orientations.

Fig. 15. AFM measurements performed on the annealed sample: (a) and (b) are topographic measurements in the close [111] crystallographic orientations with a $60^{\circ}$ and $90^{\circ}$ indenter disorientation, respectively. (c) and (d) are the corresponding derivative pictures where slip traces are highlighted using red dashed lines.

Fig. 16. Experimental (a, c, e) and numerical (b, $d, f)$ topographies obtained for the [001] indentation direction on annealed sample and for three indenter rotations: $0^{\circ}, 30^{\circ}$ and $60^{\circ}$. Comparison of the pile-up profiles ( $\mathrm{g}, \mathrm{h}$, i: experimental and numerical) along the same triangular path for the three previous indenter rotations.

Fig. 17. AFM measurements performed on the work-hardened sample: (a), (b) are topographic measurements in the close [111] crystallographic orientations with a $60^{\circ}$ and $90^{\circ}$ indenter disorientation, respectively. (c), (d) are the corresponding derivative pictures where slip traces are highlighted using red dashed lines. The dashed white circles are drawn to show that pileup lateral extension and propagation of dislocation slip lines remain confined in a plastic zone whose size does not exceed twice the size of the residual imprint. (e), (f): comparison of the 
pile-up profiles in the cold-worked and the annealed samples (see Figs. 14a and 14b) through the same triangular path.

Fig. 18. Details of a (001) Berkovich indentation plastic zone obtained on a (010) cross section: the total cumulated plastic strain (at the centre of the figure), and the ones obtained on the 12 slip systems at the maximum indentation depth (with transparent indenter). Hardening parameters used for simulating the virtual material: $q=10 \mathrm{MPa}, h_{5}=23, h_{i}=1$ (Table 2).

Fig. 19. Details of a (001) Berkovich indentation plastic zone obtained in the top view: the total cumulated plastic strain (at the centre of the figure), and the ones obtained on the 12 slip systems at the maximum indentation depth. Hardening parameters used for simulating the virtual material: $q=10 \mathrm{MPa}, h_{5}=23, h_{i}=1$ (Table 2 ).

Fig. 20. Numerical pile-up profiles sensitivity to the components of the interaction matrix. The values of the different parameters used for the simulations have been listed in the different figures. The set of simulations corresponds to a [001] indentation direction. 